Supporting Information

\title{
Bacterial cell wall modification with a glycolipid substrate
}

Phillip J. Calabretta ${ }^{1}$, Heather L. Hodges ${ }^{2}$, Matthew B. Kraft ${ }^{2}$, Victoria M. Marando ${ }^{1}$, Laura L. Kiessling ${ }^{*, 1,2,3}$

${ }^{1}$ Department of Chemistry, Massachusetts Institute of Technology, 77 Massachusetts Avenue, Cambridge, MA, 02139

2Department of Chemistry, University of Wisconsin-Madison,1101 University Avenue, Madison, WI, 53706

3Department of Biochemistry, University of Wisconsin-Madison, 433 Babcock Drive, Madison, WI, 53706

*E-mail: kiesslin@mit.edu

\section{Table of Contents}

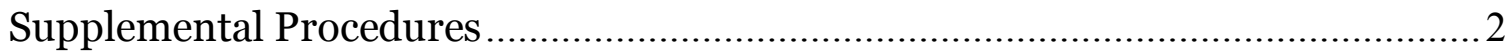

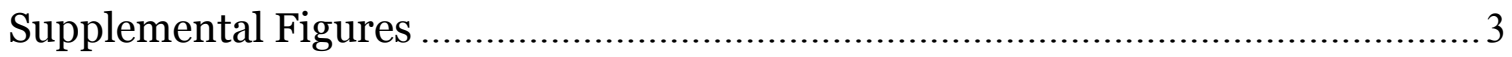

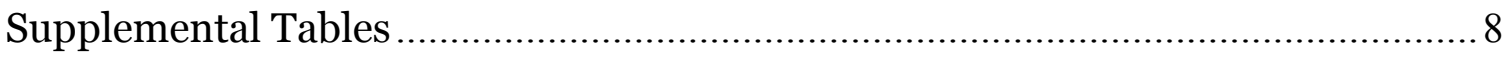

Chemical Synthesis and Characterization Data …….......................................... 9

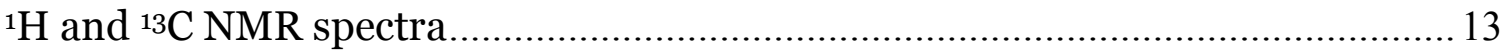

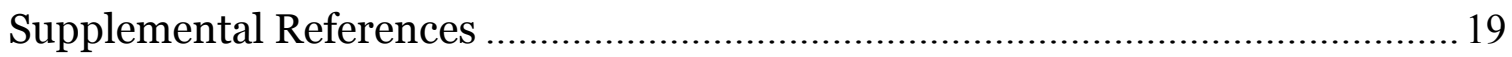




\section{Supplemental Procedures}

\section{D-NMR experimental setup}

Two-dimensional data were collected in $\mathrm{D}_{2} \mathrm{O}$ at $298 \mathrm{~K}$ on a Bruker Avance III spectrometer equipped with a $5 \mathrm{~mm}$ TCI-F or QCI-F cryoprobe. The spectral window was decreased in the $\mathrm{f} 1$ dimension to $(\mathrm{SW}=160 \mathrm{ppm}, \mathrm{O} 1=75 \mathrm{ppm})$. The ${ }^{1} \mathrm{H}-13 \mathrm{C} \mathrm{HSQC}$ experiment used was a standard pulse sequence with multiplicity editing (hsqcedetgpsisp2.3). The ${ }^{1} \mathrm{H}-{ }^{13} \mathrm{C} \mathrm{HMBC}$ experiment used was a standard sequence with no decoupling (hmbcetgpl3nd). The ${ }^{1} \mathrm{H}^{-13 \mathrm{C}}$ HSQC-TOCSY used was a standard sequence (hsqcdietgpsisp.2). Mix times used for the evolution of TOCSY peaks were $80 \mathrm{~ms}$ and $120 \mathrm{~ms}$. Spectra were processed in MestReNova.

\section{Fluorescence assays}

Fluorescence data was acquired on a Tecan Infinite M100o Pro microplate reader. Samples were prepared in Corning black 96-well microplates. Monitoring of resorufin fluorescence was achieved by exciting at $570 \mathrm{~nm} \pm 5 \mathrm{~nm}$ and detecting at $585 \mathrm{~nm} \pm 5 \mathrm{~nm}$. Z-position was set to $2 \mathrm{~mm}$, and fluorimeter gain was optimized and then kept constant between plates. Data are reported in relative fluorescence units (RFU) normalized to cell only controls.

Growth inhibition experiments with $M$. smegmatis

Corning black 96-well plates were prepared with $200 \mu \mathrm{L}$ of sterile water in the perimeter wells to prevent evaporation of the medium during incubation. A saturated culture of $M$. smegmatis in Middlebrook $7 \mathrm{H} 9$ with albumin-dextrose-catalase (ADC) enrichment and $0.05 \%$ Tween-80 was diluted to $\mathrm{OD}_{600}=0.05$ with Luria broth (LB) media containing any additives to be assayed at indicated concentrations. $100 \mu \mathrm{L}$ of culture was added to each well ( $n=3$ wells per condition). A 2-fold serial dilution of the analyte was performed. The plates were incubated with shaking at $37^{\circ} \mathrm{C}$ for $24 \mathrm{~h}$. Alamar Blue reagent $(6 \mu \mathrm{L}$, Invitrogen $)^{2}$ was added to each well and the plates were incubated again for $1 \mathrm{~h}$ at $37^{\circ} \mathrm{C}$. The fluorescence per well was then measured.

Growth inhibition experiments with C. glutamicum

Corning black 96-well plates were prepared with $200 \mu \mathrm{L}$ of sterile water in the perimeter wells to prevent evaporation of the medium during incubation. A saturated culture of $C$. glutamicum in Luria-Bertani broth was diluted to $\mathrm{OD}_{600}=0.001$ with Luria broth (LB) media containing any additives to be assayed at indicated concentrations. $100 \mu \mathrm{L}$ of culture was added to each well ( $n=3$ wells per condition). A 2-fold serial dilution of the analyte was performed. The plates were incubated with shaking at $30{ }^{\circ} \mathrm{C}$ for $16 \mathrm{~h}$. Alamar Blue reagent $(6 \mu \mathrm{L} \text {, Invitrogen })^{2}$ was added to each well and the plates were incubated again for $1 \mathrm{~h}$ at $30^{\circ} \mathrm{C}$. The fluorescence per well was then measured. 


\section{Supplemental Figures}
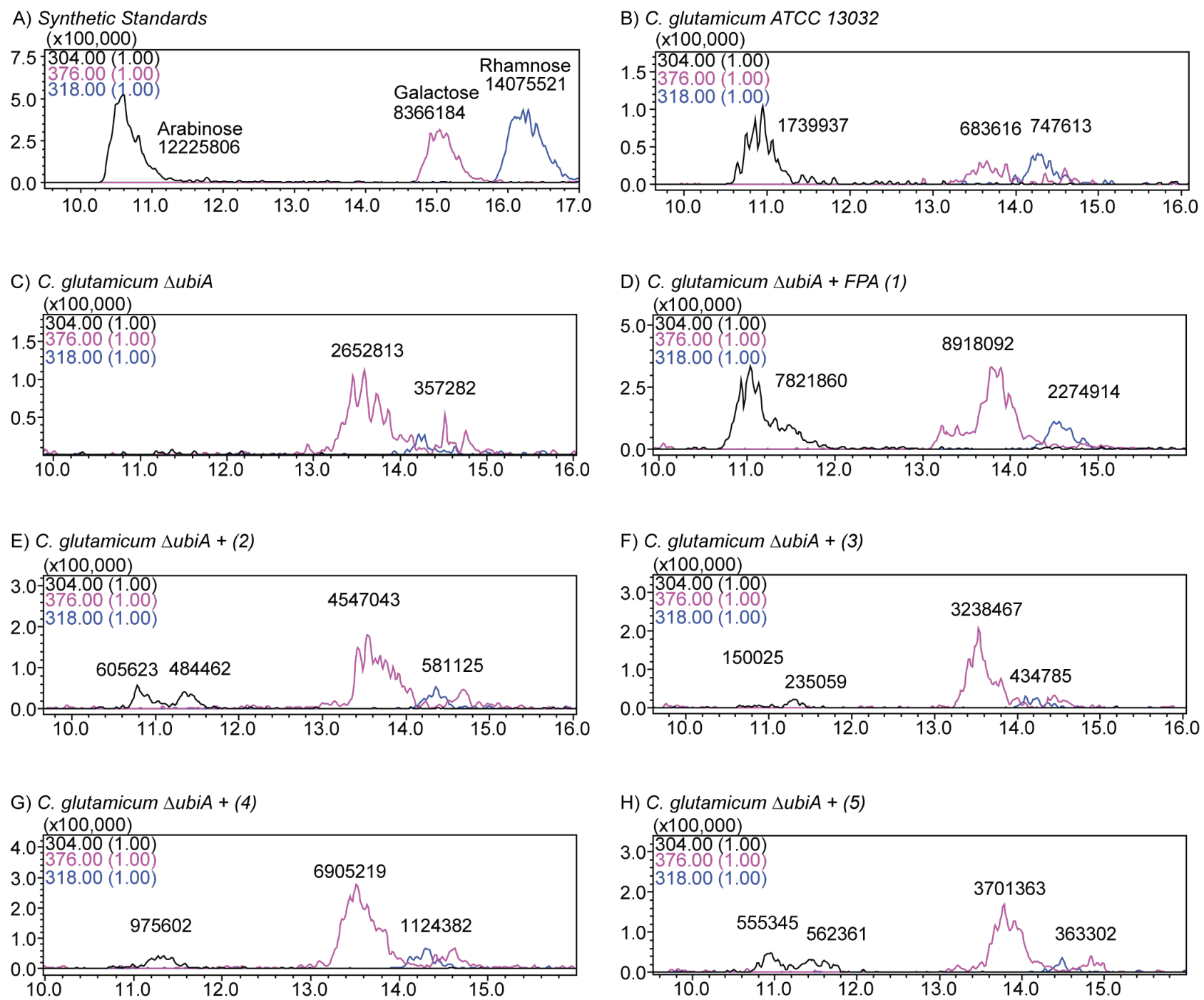

H) C. glutamicum $\triangle u b i A+(5)$
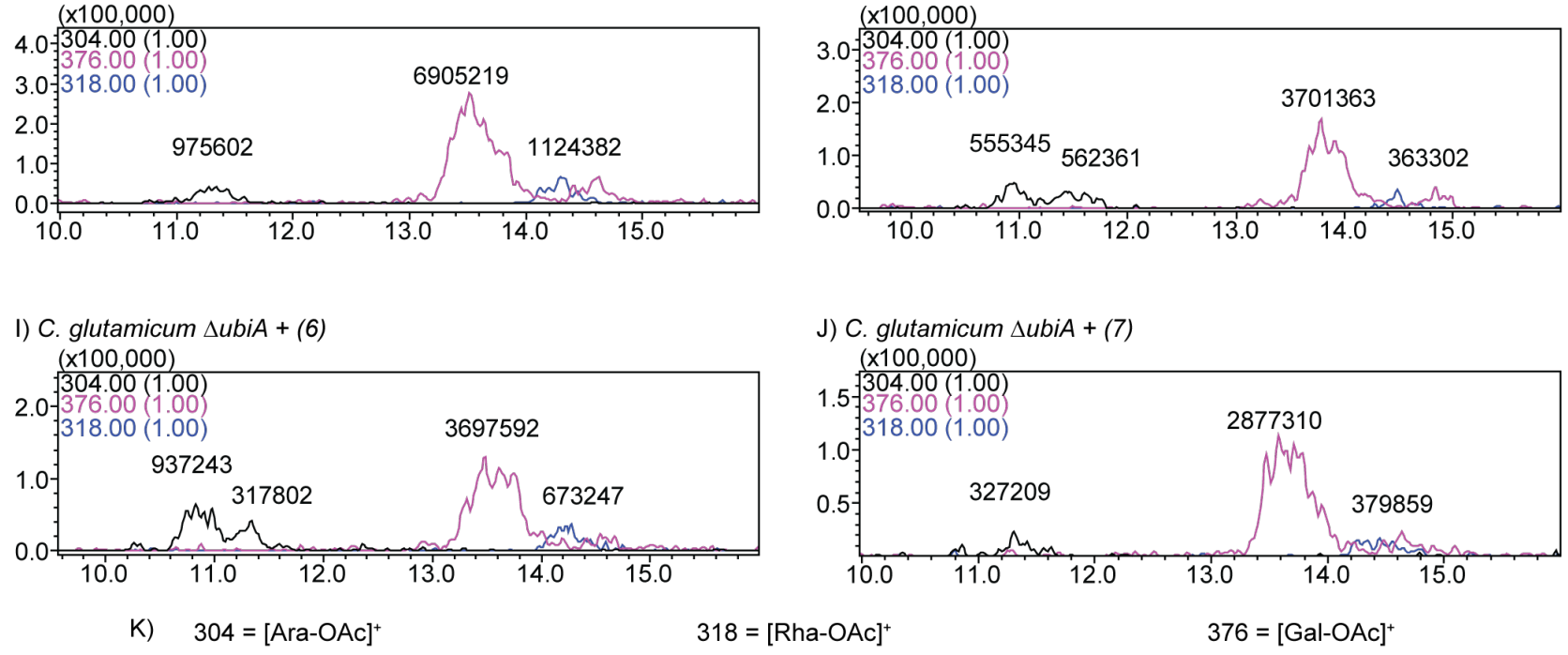

Figure S1. Composition analysis of data depicted in Figure 3 of text. A) Synthetic alditol acetate standards of arabinose (Ara), rhamnose (Rha), and galactose (Gal); B) arabinogalactan from Cg ATCC 13032; C) galactan from $C g \Delta u b i A$; D) arabinogalactan from $C g \Delta u b i A$ treated with FPA (1), E) arabinogalactan from $C g \Delta u b i A$ treated with $250 \mu \mathrm{M}$ compound $\mathbf{2}$; F) arabinogalactan from $C g \Delta u b i A$ treated with $250 \mu \mathrm{M}$ compound $3 ; \mathrm{G}$ ) arabinogalactan from $\mathrm{Cg} \Delta u b i A$ treated with $250 \mu \mathrm{M}$ compound 4 ; H) arabinogalactan from $C g \Delta u b i A$ treated with $250 \mu \mathrm{M}$ compound 5 ; I) arabinogalactan from $C g \Delta u b i A$ treated with $250 \mu \mathrm{M}$ compound 6; J) arabinogalactan from $C g \Delta u b i A$ treated with $250 \mu \mathrm{M}$ compound 7 . Ratios were determined based on the ion counts of the $[\mathrm{M}-\mathrm{OAc}]^{+}$signals for the monodeuterated alditol acetates of arabinose, galactose, and rhamnose. 
A

${ }^{1} \mathrm{H}-{ }^{13} \mathrm{C}$ HSQC

C. glutamicum ATCC $13032 \mathrm{CH} / \mathrm{CH}_{3}$

C. glutamicum ATCC $13032 \mathrm{CH}_{2}$

B

${ }^{1} \mathrm{H}-{ }^{13} \mathrm{C}$ HSQC

C. glutamicum $\triangle u b i A$

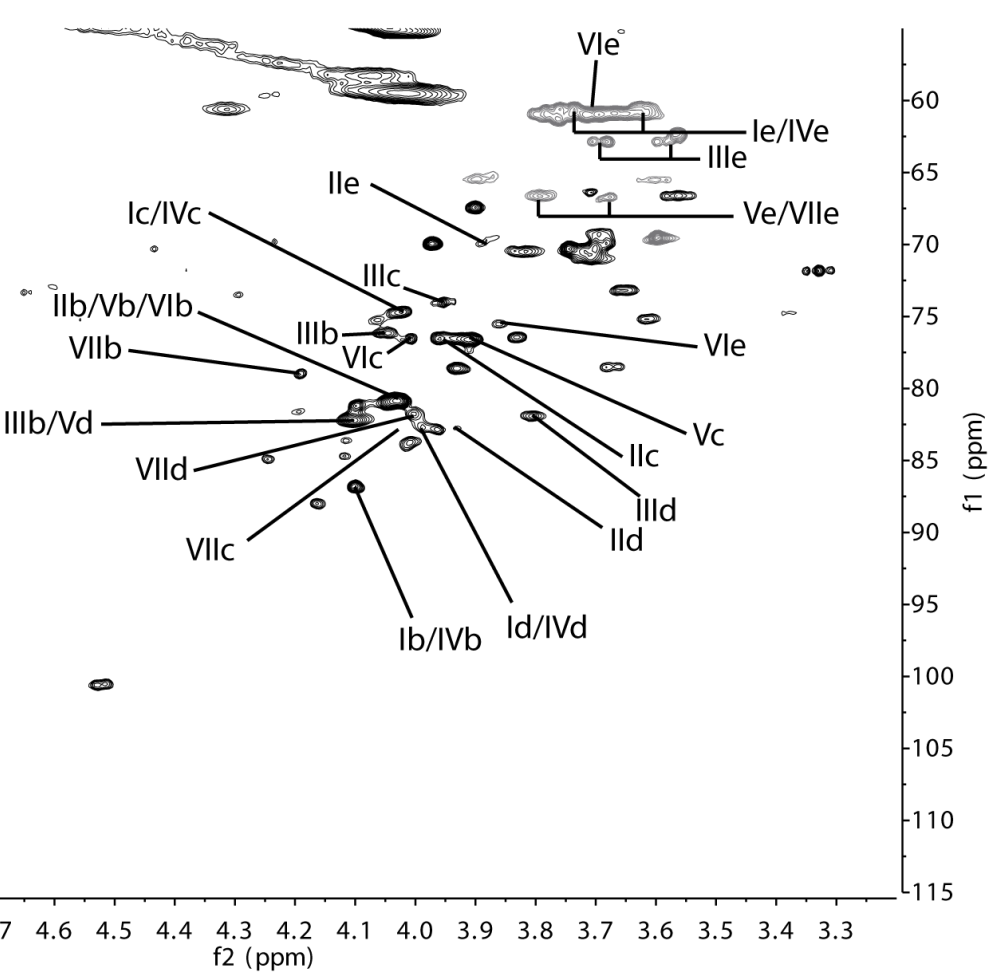

$\begin{array}{llllllllllllllllllllll}5.3 & 5.2 & 5.1 & 5.0 & 4.9 & 4.8 & 4.7 & 4.6 & 4.5 & 4.4 & \begin{array}{c}4.3 \\ \mathrm{f} 2\end{array}(\mathrm{ppm}) & 4.2 & 4.0 & 3.9 & 3.8 & 3.7 & 3.6 & 3.5 & 3.4 & 3.3\end{array}$

$B$
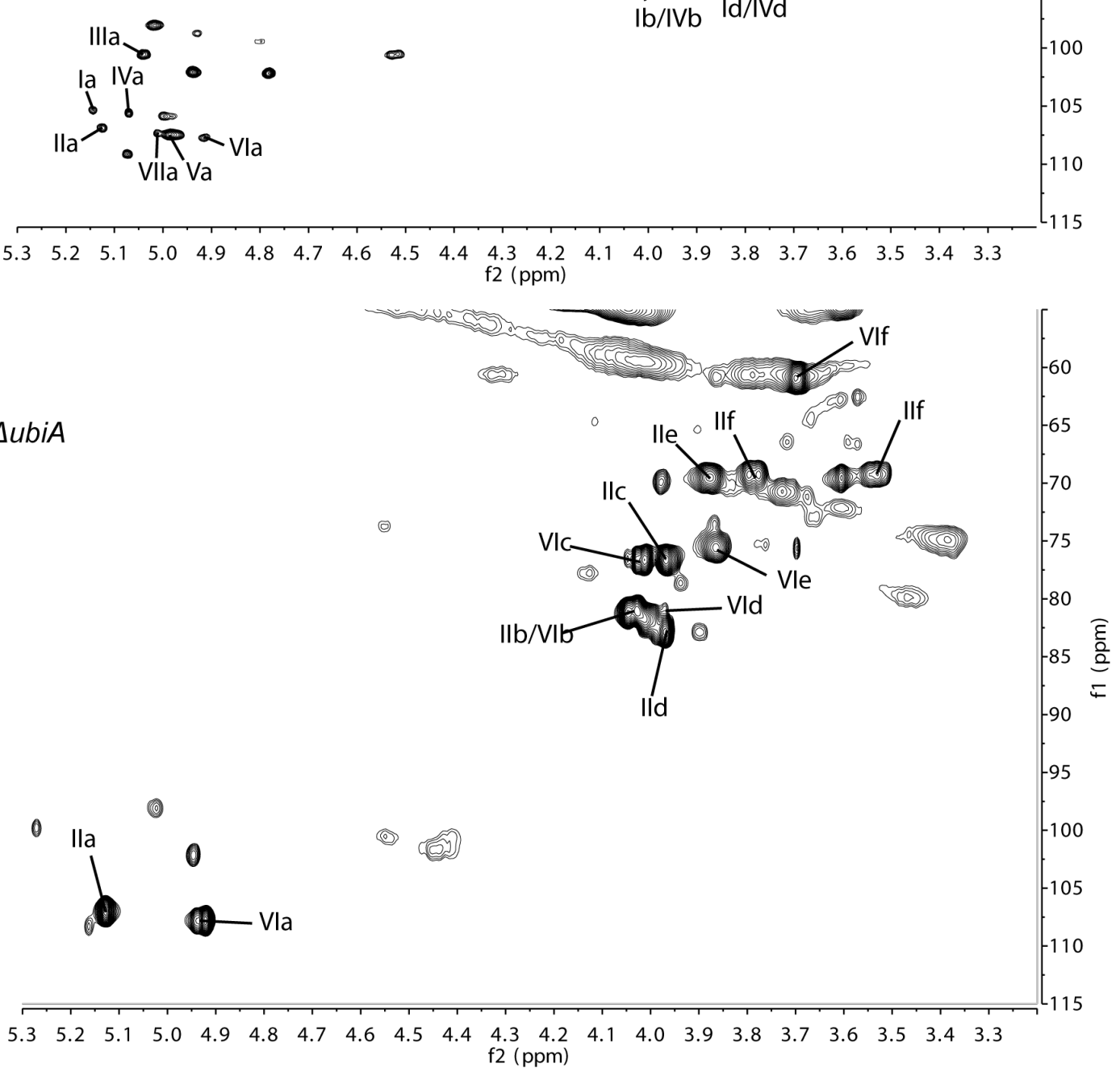

Figure S2. ${ }^{1} \mathrm{H}-13 \mathrm{C}$ HSQC of arabinogalactan (A) isolated from $\mathrm{Cg}$ ATCC 13032 and galactan (B) from untreated $\mathbf{C g \Delta u b i A}$. Spectra were obtained at $600 \mathrm{MHz}$ in $\mathrm{D}_{2} \mathrm{O}$ at $298 \mathrm{~K}$. Relevant peaks are tabulated in Table S1. 
${ }^{1} \mathrm{H}-{ }^{13} \mathrm{C}$ HSQC-TOCSY

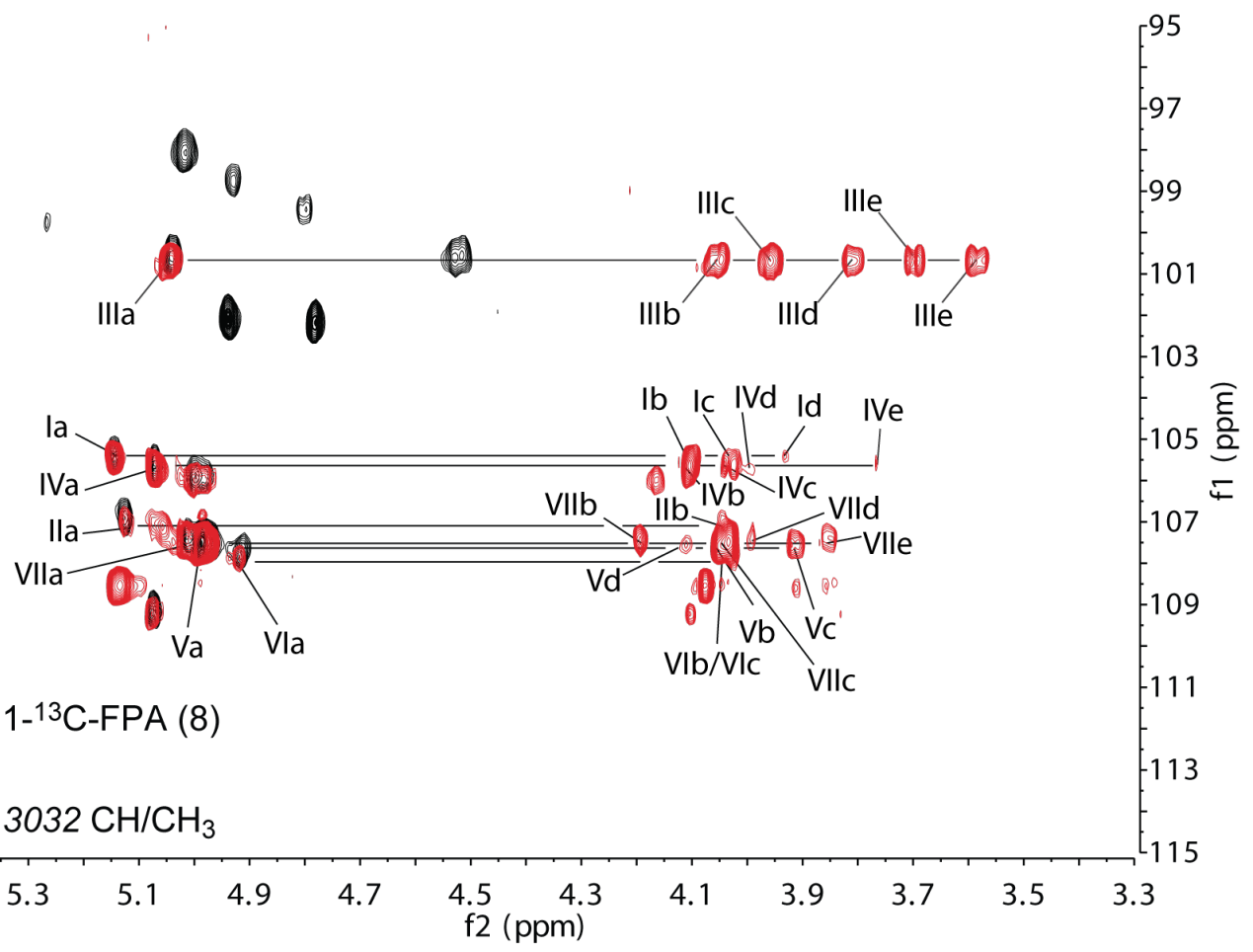

Figure S3. ${ }^{1} \mathrm{H}-13 \mathrm{C}$ HSQC-TOCSY of the recovered arabinogalactan from $\mathrm{Cg} \Delta u b i A$ (red) stacked on the ${ }^{1 H-13 C}$ HSQC of arabinogalactan from $C g$ ATCC 13032 (black). Relevant peaks are tabulated in Table S1.

${ }^{1} \mathrm{H}-{ }^{13} \mathrm{C} \mathrm{HMBC}$

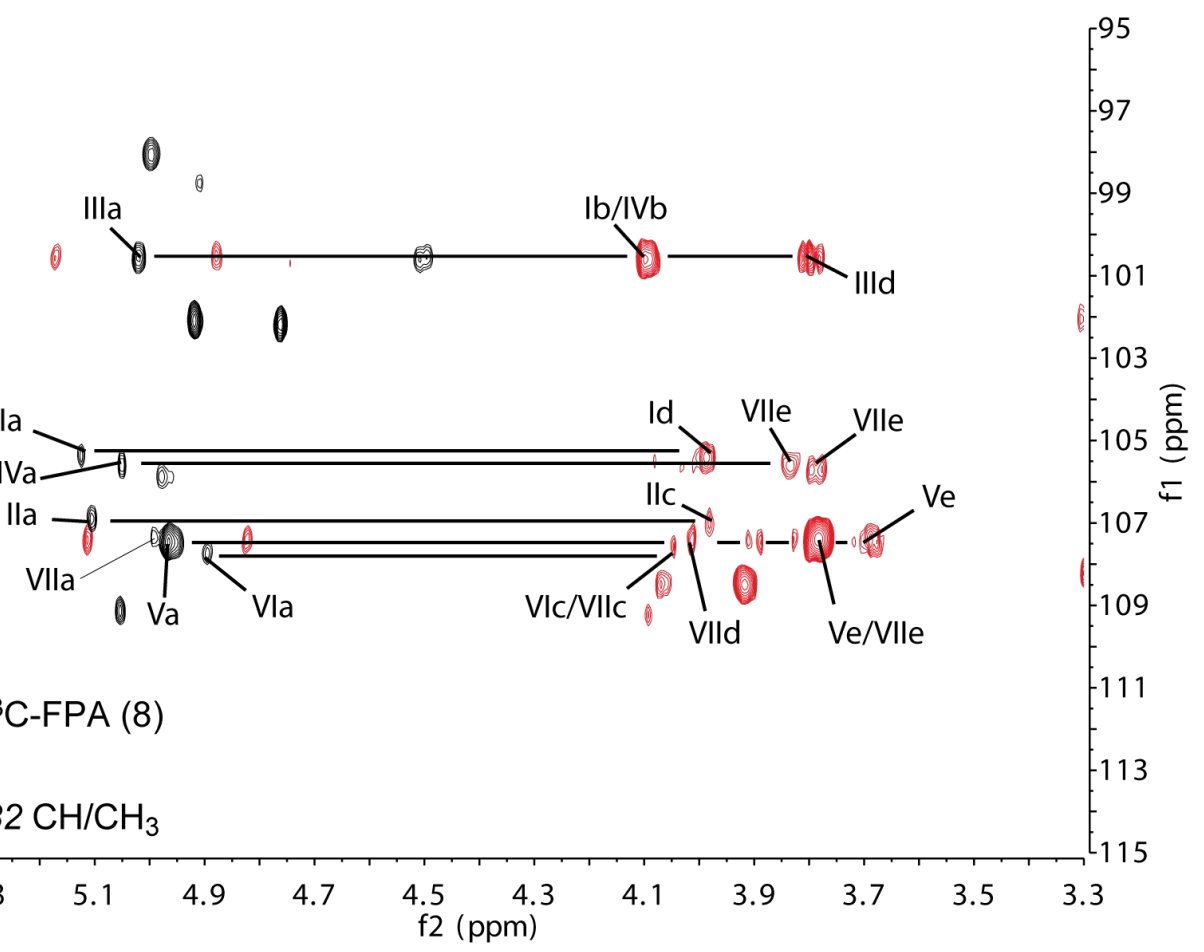

Figure S4. ${ }^{1} \mathrm{H}-13 \mathrm{C}$ HMBC of the recovered arabinogalactan from $\mathrm{Cg} \Delta u b i A$ (red) stacked on the 1H-13C HSQC of arabinogalactan from $C g$ ATCC 13032 (black). Relevant peaks are tabulated in Table S1. 
A

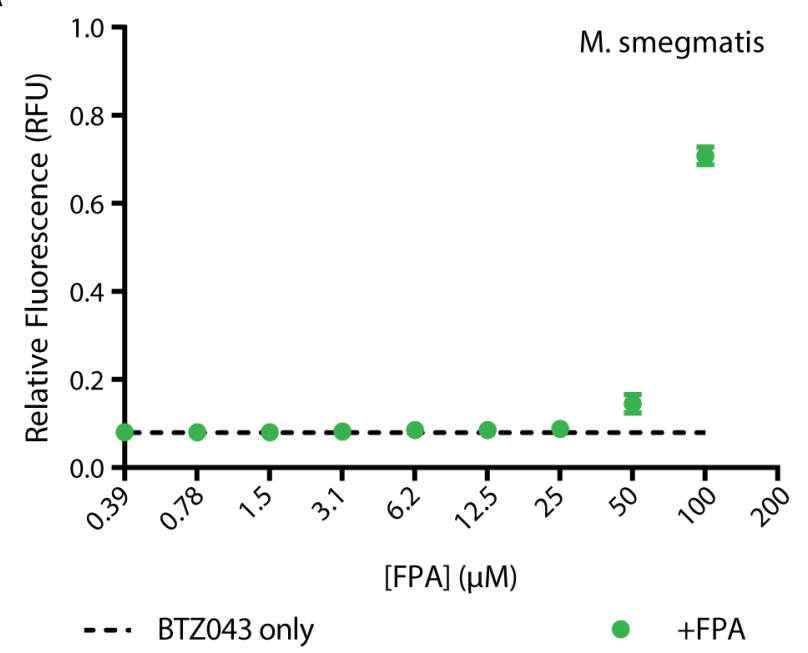

B

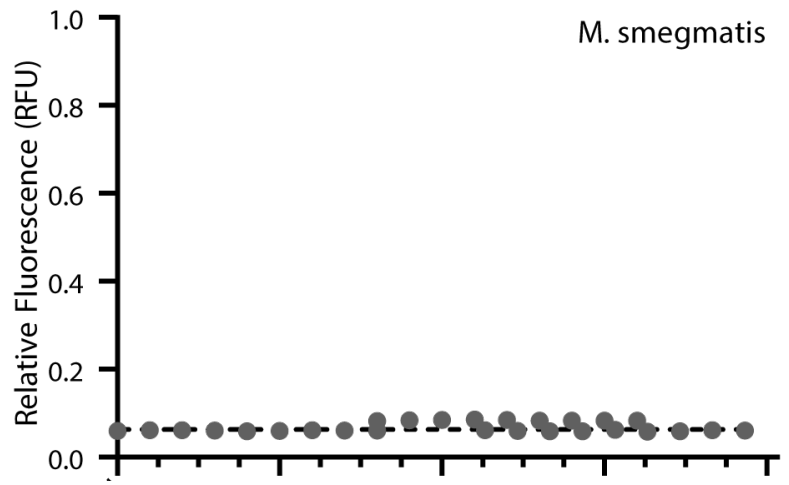

Figure S5. Concentration dependence of A) FPA (1)-mediated and B) (Z,Z)-farnesyl phosphate -mediated rescue of BTZo43 treated $M$. smegmatis. Growth of $M$. smegmatis $m c^{2} 155$ was measured, via the Alamar Blue assay, in the presence of $6 \mathrm{ng} / \mathrm{mL}$ BTZo43 and FPA (1) $(100-0.39 \mu \mathrm{M})$ or $(\mathrm{Z}, \mathrm{Z})$-farnesyl phosphate $(100 \mu \mathrm{M}-150 \mathrm{pM})$. Data for B were collected over three independent experiments. The $Y$ axis depicts the relative fluorescence compared to an untreated control sample. For points lacking error bars the error was too small to be depicted graphically. Error bars represent the standard deviation, $\mathrm{n}=3$. 


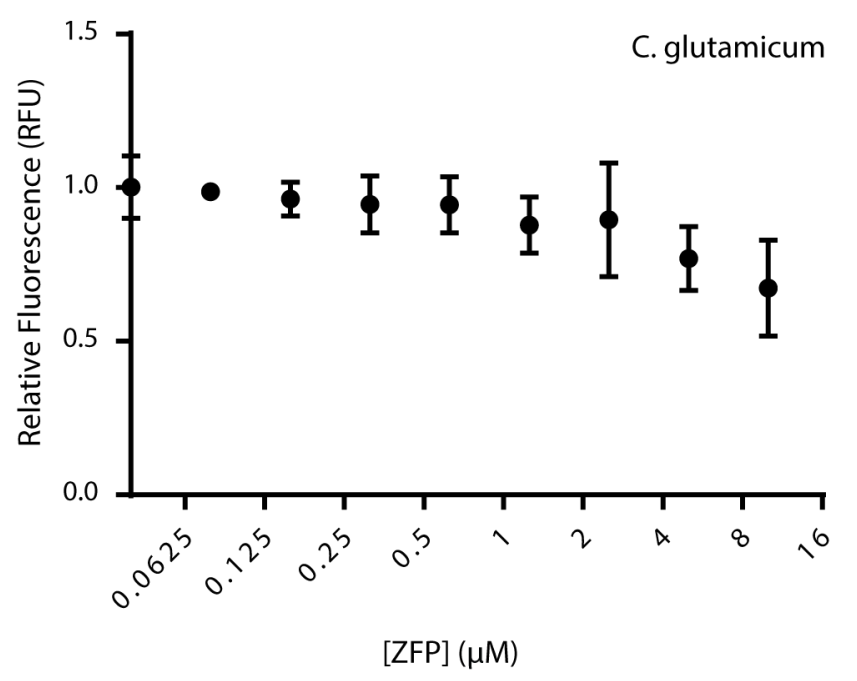

Figure S6. (Z,Z)-Farnesyl phosphate (ZFP)- induced toxicity was assessed in C. glutamicum ATCC 13032 in the absence of other additives. Growth of C. glutamicum ATCC 13032 was measured, via the Alamar Blue assay, in the presence of $(\mathrm{Z}, \mathrm{Z})$-farnesyl phosphate $(10-0.313 \mu \mathrm{M})$. The $\mathrm{Y}$ axis depicts the relative fluorescence compared to an untreated control sample. For points lacking error bars the error was too small to be depicted graphically. Error bars represent the standard deviation, $n=3$.

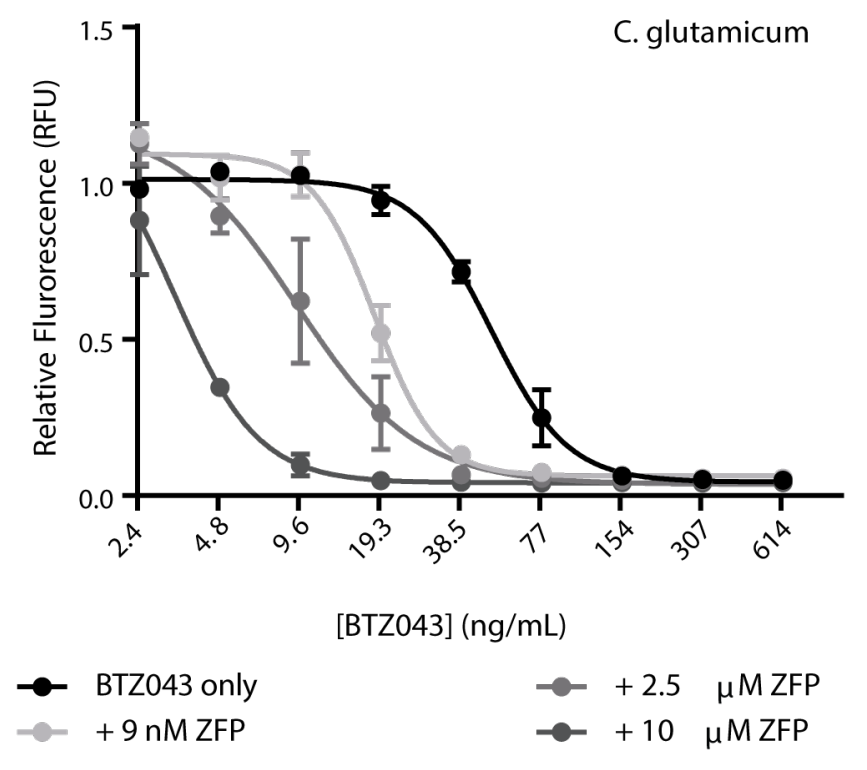

Figure S7. The effect of ZFP on BTZo43 toxicity was assessed for different concentrations of ZFP. Growth of C. glutamicum ATCC 13032 was measured, via the Alamar Blue assay, in the presence of BTZo43 $(625 \mathrm{nM}-2.4 \mathrm{nM})$ and ZFP (9 nM, 2.5 $\mu \mathrm{M}$, or $10 \mu \mathrm{M})$. The Y axis depicts the relative fluorescence compared to an untreated control sample. For points lacking error bars the error was too small to be depicted graphically. Error bars represent the standard deviation, $n=3$. 


\section{Supplemental Tables}

Table S1. Key chemical shifts from the characterization of the $1{ }^{13} \mathrm{C}$ labeled and unlabeled arabinogalactan.

\begin{tabular}{|c|c|c|c|c|c|c|c|c|}
\hline \multirow[b]{2}{*}{ Signal } & \multirow[b]{2}{*}{ Residue } & & \multicolumn{6}{|c|}{ Chemical shift (ppm) } \\
\hline & & & $\mathrm{a}$ & $\mathrm{b}$ & c & d & e & $\mathrm{f}$ \\
\hline \multirow{2}{*}{ I } & \multirow{2}{*}{$2-\alpha-\operatorname{Ara} f^{*}$} & ${ }^{1} \mathrm{H}$ & 5.16 & $4.11^{\#}$ & $4.04^{\#}$ & $3.98^{\#}$ & $3.74 / 3.63^{\#}$ & - \\
\hline & & ${ }^{13} \mathrm{C}$ & 105.44 & $86.89^{\#}$ & $74 \cdot 77^{\#}$ & $82.83^{\#}$ & $60.66^{\#}$ & - \\
\hline \multirow{2}{*}{ II } & \multirow{2}{*}{ 6- $\beta-\mathrm{Gal} f$} & ${ }^{1} \mathrm{H}$ & 5.14 & $4.04^{\#}$ & $3.98^{\#}$ & $3.94^{\#}$ & $3.88^{\#}$ & $3.79 / 3.54$ \# \\
\hline & & ${ }^{13} \mathrm{C}$ & 106.88 & $80.90^{\#}$ & $76.56^{\#}$ & $82.83^{\#}$ & $69.76^{\#}$ & $69.23^{\#}$ \\
\hline \multirow{2}{*}{ III } & \multirow{2}{*}{$\mathrm{t}-\beta-\operatorname{Ara} f$} & ${ }^{1} \mathrm{H}$ & 5.05 & $4.05^{\#}$ & $3.97^{\#}$ & $3.81^{\#}$ & $3.69 / 3.59^{\#}$ & - \\
\hline & & ${ }^{13} \mathrm{C}$ & 100.62 & $76.14^{\#}$ & $74.23^{\#}$ & $81.96^{\#}$ & $62.88^{\#}$ & - \\
\hline \multirow{2}{*}{ IV } & \multirow{2}{*}{$2-\alpha-\operatorname{Ara} f^{7}$} & ${ }^{1} \mathrm{H}$ & 5.08 & $4.11^{\#}$ & $4.04^{\#}$ & $3.98^{\#}$ & $3.74 / 3.63^{\#}$ & - \\
\hline & & ${ }^{13} \mathrm{C}$ & 105.62 & $86.89^{\#}$ & $74 \cdot 77^{\#}$ & $82.83^{\#}$ & $60.66^{\#}$ & - \\
\hline \multirow{2}{*}{ V } & \multirow{2}{*}{ 5- $\alpha$-Ara $f$} & ${ }^{1} \mathrm{H}$ & 5.00 & $4.04^{\#}$ & $3.92^{\#}$ & $4.11^{\#}$ & $3.80 / 3.71^{\#}$ & - \\
\hline & & ${ }^{13} \mathrm{C}$ & 107.48 & $80.90^{\#}$ & $76.68^{\#}$ & $82.14^{\#}$ & $66.56^{\#}$ & - \\
\hline \multirow{2}{*}{ VI } & \multirow{2}{*}{ 5- $\beta-$ Gal $f$} & ${ }^{1} \mathrm{H}$ & 4.93 & $4.04^{\#}$ & $4.02^{\#}$ & $3.97^{\#}$ & $3.87^{\#}$ & $3.71^{\#}$ \\
\hline & & ${ }^{13} \mathrm{C}$ & 107.73 & $80.90^{\#}$ & $76.59^{\#}$ & $81.2 \mathrm{C} 8^{\#}$ & $75.57^{\#}$ & $60.99^{\#}$ \\
\hline \multirow{2}{*}{ VII } & \multirow{2}{*}{ 3,5- $\alpha-\operatorname{Ara} f$} & ${ }^{1} \mathrm{H}$ & 5.03 & $4.21^{\#}$ & $4.03^{\#}$ & $3.98^{\#}$ & $3.80 / 3 \cdot 76^{\#}$ & - \\
\hline & & ${ }^{13} \mathrm{C}$ & 107.41 & $78.98^{\#}$ & $82.77^{\#}$ & $82.00^{\#}$ & $66.43^{\#}$ & - \\
\hline \multirow{2}{*}{ VIII } & \multirow{2}{*}{$5,6-\beta$-Galf } & ${ }^{1} \mathrm{H}$ & 5.07 & - & - & - & - & - \\
\hline & & ${ }^{13} \mathrm{C}$ & 107.10 & - & - & - & - & - \\
\hline
\end{tabular}

${ }^{*} C_{3}$ (3,5- $\alpha$-Araf); $7 C_{5}$ (3,5- $\alpha$-Araf); ${ }^{\#}$ Values based on characterization of arabinogalactan from C. glutamicum ATCC 13032. Peak assignments are based on work by Chatterjee and coworkers. ${ }^{1}$ 


\section{Chemical Synthesis and Characterization Data}

General information. All chemicals were purchased from Sigma Aldrich unless otherwise stated. BTZ043 was purchased from Ark Pharm (AK546310). Unlabeled DPA analogs (1-7) were prepared as previously reported. ${ }^{3} 1^{-13} \mathrm{C}-\mathrm{D}$-arabinose was purchased from Cambridge Isotope Labs (CLM-715). $1^{-13} \mathrm{C}-(Z, Z)$-farnesyl phosphoryl- $\beta$-Darabinofuranose (8) (Scheme S1) was prepared following a previously published route. 3 Farnesyl phosphate was purchased from Isoprenoids, LLC (2z6zFPo03). Dry solvents were obtained from a solvent purification system (Pure Process Technologies) under argon, unless otherwise stated. DMF and pyridine were used from sure seal bottles (Sigma Aldrich) without further purification. Triethylamine was distilled from $\mathrm{CaH}_{2}$ just prior to use.

Analytical thin layer chromatography (TLC) was performed on EMD Millipore ${ }^{\mathrm{TM}}$ TLC silica gel $60 \mathrm{~F}_{254}$ (glass-backed). Plates were visualized under UV light and by staining with $p$ anisaldehyde stain with charring. Flash chromatography was performed on SiliCycle $®$ SiliaFlash ${ }^{\circledR}$ P6o silica gel.

Nuclear magnetic resonance spectra were recorded on a $300 \mathrm{MHz}$ spectrometer (acquired at $300 \mathrm{MHz}$ for ${ }^{1} \mathrm{H}$ and $75 \mathrm{MHz}$ for ${ }^{13} \mathrm{C}$ ), $400 \mathrm{MHz}$ spectrometer (acquired at $400 \mathrm{MHz}$ for ${ }^{1} \mathrm{H}$ and $100 \mathrm{MHz}$ for ${ }^{13} \mathrm{C}$ ), or a $500 \mathrm{MHz}$ spectrometer (acquired at $500 \mathrm{MHz}$ for ${ }^{1} \mathrm{H}$ and 125 $\mathrm{MHz}$ for ${ }^{13 \mathrm{C}}$ ). Chemical shifts are reported relative to tetramethylsilane or residual solvent peaks in parts per million $\left(\mathrm{CHCl}_{3}:{ }^{1} \mathrm{H}, 7.27,{ }^{13} \mathrm{C}, 77.23\right.$; $\left.\mathrm{MeOH}:{ }^{1} \mathrm{H}, 3.31,{ }^{13} \mathrm{C}, 49.15\right)$. High resolution mass spectra (HRMS) were obtained on an electrospray ionization-time of flight (ESI-TOF) mass spectrometer.

\section{Synthetic scheme for 1-13C-FPA (8)}
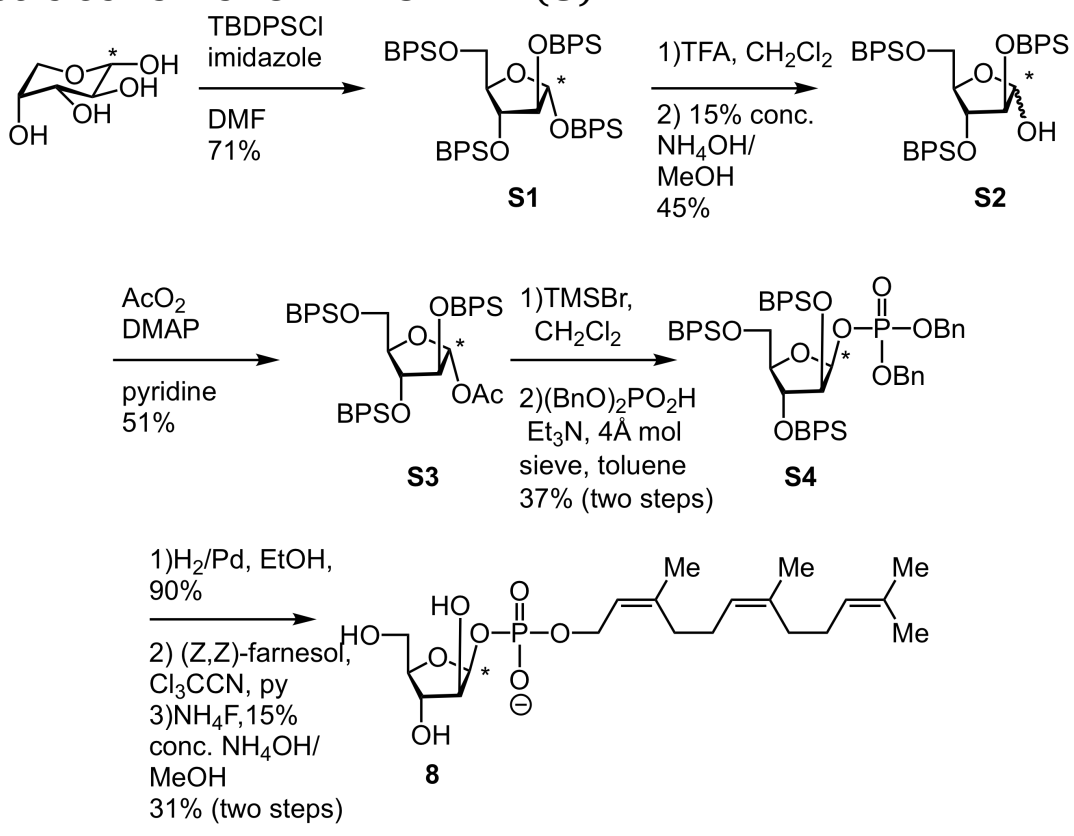
1,2,3,5-Tetra-O-tert-butyldiphenylsilyl-1-13C-D-arabinofuranose (S1). 1-13C-Darabinose (0.5099g, $3.31 \mathrm{mmol}$, Cambridge Isotope Labs) and imidazole (1.57 g, 23.2 $\mathrm{mmol})$ were azeotropically dried with toluene $(2 \times 3 \mathrm{~mL})$ in flame dried flask. The resulting residue was dissolved in anhydrous DMF $(22.1 \mathrm{~mL}, 0.15 \mathrm{M})$. To the stirring solution was added TBDPSCl $(4.7 \mathrm{~mL}, 20 \mathrm{mmol})$ dropwise. The reaction was stirred at $70^{\circ} \mathrm{C}$ for $48 \mathrm{~h}$. The reaction was quenched by the addition of diethanolamine $(1.3 \mathrm{~mL}, 9.9 \mathrm{mmol})$ and then stirred at $70^{\circ} \mathrm{C}$ for $2 \mathrm{~h}$. The quenched reaction was poured into a stirring mixture of water $(150 \mathrm{~mL})$ and $15 \%$ EtOAc in hexanes $(150 \mathrm{~mL})$. The phases were separated, and the aqueous phase was extracted with $15 \%$ EtOAc in hexanes $(150 \mathrm{~mL})$. The combined organic phase was dried over $\mathrm{Na}_{2} \mathrm{SO}_{4}$, filtered, and concentrated under reduced pressure. After flash chromatography over silica eluting with $4 \%$ EtOAc in hexanes. The product was obtained as a light-yellow foam (2.657 g, $71 \%$ ). ${ }^{1} \mathrm{H}$ NMR $\left(500 \mathrm{MHz}, \mathrm{CDCl}_{3}\right) \delta 7.76-7.44$ (m, $13 \mathrm{H}), 7.41-6.99(\mathrm{~m}, 32 \mathrm{H}), 5.23(\mathrm{~d}, J=172.4 \mathrm{~Hz}, 1 \mathrm{H}), 4.52$ (ddd, $J=7.2,5.3,2.3 \mathrm{~Hz}$, $1 \mathrm{H}), 4.3 \mathrm{O}(\mathrm{s}, 1 \mathrm{H}), 4.1 \mathrm{O}(\mathrm{t}, J=2.5 \mathrm{~Hz}, 1 \mathrm{H}), 3.53(\mathrm{dd}, J=10.4,7.2 \mathrm{~Hz}, 1 \mathrm{H}), 3.42$ (dd, $J=10.5$, $5.2 \mathrm{~Hz}, 1 \mathrm{H}), 1.00(\mathrm{~s}, 9 \mathrm{H}), 0.97(\mathrm{~s}, 9 \mathrm{H}), 0.97(\mathrm{~s}, 9 \mathrm{H}), 0.7 \mathrm{O}(\mathrm{s}, 9 \mathrm{H}) .{ }^{13 \mathrm{C}} \mathrm{NMR}(126 \mathrm{MHz}$, $\left.\mathrm{CDCl}_{3}\right) \delta 136.20,136.01,135.91,135.89,135.86,135.77,135.73,135.62,135.61,135.59$, 135.57, 135.54, 135.51, 135.49, 133.93, 133.61, 133.45, 133.30, 133.17, 132.72, 129.61, 129.53, $129.49,129.44,129.37,129.33,129.28,127.60,127.59,127.55,127.53$, 127.50, 127.49, $127.43,127.36,127.30,127.2,103.6,99.6,88.6,84.5$ (d, $J=48.0 \mathrm{~Hz}), 81.0$ (d, $J=1.2 \mathrm{~Hz})$, $65.2,26.9,26.8,26.7,26.6,19.2,19.17,19.14,18.8$. HRMS (ESI-TOF ${ }^{+}$) calc'd for $\mathrm{C}_{68}{ }^{13} \mathrm{CH}_{90} \mathrm{NO}_{5} \mathrm{Si}_{4}\left(\mathrm{M}+\mathrm{NH}_{4}{ }^{+}\right) 1121.5612$, found 1121.5607 .

2,3,5-Tri-O-tert-butyldiphenylsilyl-1-13C-o-arabinofuranose (S2). To a stirring solution of $\mathbf{S 1}$ (1.4956 g, $1.35 \mathrm{mmol}$ ) in dichloromethane (13.5 mL, 0.1 M) was added dropwise trifluoracetic acid $(3.4 \mathrm{~mL}, 45 \mathrm{mmol})$ and the resulting solution was stirred for 5 min. Meanwhile, a flask containing a $15 \%$ conc. $\mathrm{NH}_{4} \mathrm{OH}$ in methanol $(98 \mathrm{~mL})$ was cooled to $-15^{\circ} \mathrm{C}$ in a glycerol dry ice bath. When the trifluoracetic acid (TFA) solution had stirred for $5 \mathrm{~min}$, it was poured slowly into the stirring, chilled base. Stirring was continued for $2 \mathrm{~h}$ at $-15{ }^{\circ} \mathrm{C}$. The biphasic mixture was warmed to room temperature and partitioned between a 1:1 mixture of dichloromethane $(75 \mathrm{~mL})$ and $\mathrm{H}_{2} \mathrm{O}(75 \mathrm{~mL})$. The phases were separated, and the aqueous phase was washed with dichloromethane $(3 \times 75 \mathrm{~mL})$. The combined organic phase was dried over $\mathrm{Na}_{2} \mathrm{SO}_{4}$, filtered and evaporated under reduced pressure. The product was obtained by flash column chromatography on silica gel eluting with $4 \%$ EtOAc in hexanes. The product containing fractions were pooled and evaporated under reduced pressure to provide $\mathbf{S 2}(0.5244 \mathrm{~g}, 45 \%)$ as a white foam. ${ }^{1} \mathrm{H}$ NMR (500 $\left.\mathrm{MHz}, \mathrm{CDCl}_{3}\right) \delta 7.74$ - 7.06 (m, 45H), $5.49-5.42$ (ddd, , $J=173.0,12.5,3.3 \mathrm{~Hz}, 0.25 \mathrm{H}, \mathrm{H}-1$ [beta]), $5.34-4.88$ (dd, $J=175.7,11.8 \mathrm{~Hz}, 0.75 \mathrm{H}, \mathrm{H}-1[$ alpha]), $4.57(\mathrm{t}, J=6.9 \mathrm{~Hz}, 1 \mathrm{H}), 4.22$ (d, $J=4.2 \mathrm{~Hz}$, $1 \mathrm{H}), 4.06(\mathrm{~d}, J=1.5 \mathrm{~Hz}, 1 \mathrm{H}), 3.72(\mathrm{dd}, J=10.2,6.7 \mathrm{~Hz}, 1 \mathrm{H}), 3.68(\mathrm{dd}, J=12.0,4.6 \mathrm{~Hz}, 1 \mathrm{H})$, $3.58-3.48(\mathrm{~m}, 1 \mathrm{H}), 0.98$ (s, $3 \mathrm{H}), 0.96(\mathrm{~d}, J=1.3 \mathrm{~Hz}, 18 \mathrm{H}), 0.92(\mathrm{~s}, 3 \mathrm{H}), 0.89(\mathrm{~s}, 3 \mathrm{H}), 0.81$ (s, 9H). ${ }^{13} \mathrm{C} \mathrm{NMR}\left(126 \mathrm{MHz}, \mathrm{CDCl}_{3}\right.$ ) $\delta$ 135.75, 135.69, 135.68, 135.62, 135.60, 135.55, 135.51, 135.47, 133.55, 133.30, 133.30, 133.17, 132.97, 132.79, 132.68, 132.35, 132.26, 132.23, 132.13, 131.99, 130.01, 129.91, 129.90, 129.82, 129.53, 129.49, 127.84, 127.82, 127.75, 127.72, 127.61, 127.59, 127.57, 127.57, 103.78, 98.49, 88.67, 85.27, 83.53, 81.03 (d), 79.14, 78.49 (d), 77.85, 77.82, 76.75, 64.95, 26.85, 26.82, 19.12, 19.11, 19.09, 19.05, 18.97, 18.85 . HRMS (ESI-TOF ${ }^{+}$) calc'd for $\mathrm{C}_{52}{ }^{13} \mathrm{CH}_{68} \mathrm{NO}_{5} \mathrm{Si}_{3}\left(\mathrm{M}+\mathrm{NH}_{4}{ }^{+}\right.$) 883.4434, found 883.4452.

1-O-Acetyl-2,3,5-Tri-O-tert-butyldiphenylsilyl-1-13C- $\mathrm{B}$-D-arabinofuranose (S3). S2 was azeotropically dried with toluene $(3 \times 10 \mathrm{~mL})$. Pyridine was added, and the mixture 
was stirred until S2 had dissolved. 4-Dimethylaminopyridine (DMAP) and acetic anhydride were added to the stirred solution and stirring was continued for $3 \mathrm{~h}$ at rt. The solution was quenched by the addition of saturated aqueous $\mathrm{NaHCO}_{3}$ solution. The mixture was diluted with dichloromethane and the phases were separated. The aqueous phase was washed with additional dichloromethane. The combined organic phase was dried over $\mathrm{Na}_{2} \mathrm{SO}_{4}$, filtered, and the solvent removed under reduced pressure. The product was obtained by flash column chromatography on silica gel eluting with $4 \%$ EtOAc in hexanes. The product containing fractions were pooled and evaporated under reduced pressure to provide $\mathbf{S 3}(0.2822 \mathrm{~g}, 51 \%)$ as a colorless, highly viscous oil. ${ }^{1} \mathrm{H}$ NMR (500 $\left.\mathrm{MHz}, \mathrm{CDCl}_{3}\right) \delta 7.91-6.94(\mathrm{~m}, 3 \mathrm{OH}), 5.98\left(\mathrm{~d}, J_{\mathrm{HC}}=179.5 \mathrm{~Hz}, 1 \mathrm{H}\right), 4.53-4.45$ (ddd, $1 \mathrm{H}$ ), $4.37-4.31(\mathrm{dd}, 1 \mathrm{H}), 4.17(\mathrm{~s}, 1 \mathrm{H}), 3.67(\mathrm{dd}, J=10.3,6.4 \mathrm{~Hz}, 1 \mathrm{H}), 3.50(\mathrm{dd}, J=10.3,7.3 \mathrm{~Hz}$, $1 \mathrm{H}), 1.94(\mathrm{~s}, 3 \mathrm{H}), 0.98(\mathrm{~s}, 9 \mathrm{H}), 0.96(\mathrm{~s}, 9 \mathrm{H}), 0.84(\mathrm{~s}, 9 \mathrm{H}) .{ }^{13 \mathrm{C} \mathrm{NMR}}\left(126 \mathrm{MHz}, \mathrm{CDCl}_{3}\right) \delta$ 169.66 (d), 135.71, 135.69, 135.65, 135.54, 135.51, 133.49, 133.24, 133.22, 133.05, 132.51, $132.39,129.87,129.77,129.73,129.67,129.56,129.51,127.69,127.67,127.63,127.59$, 102.38, 94.72, 90.25, 82.37, 78.89 (d), 64.57, 26.80, 26.67, 26.66, 21.06, 19.16, 19.13, 18.88. HRMS (ESI-TOF ${ }^{+}$calc'd for $\mathrm{C}_{54}{ }^{13} \mathrm{CH}_{70} \mathrm{NO}_{6} \mathrm{Si}_{3}\left(\mathrm{M}+\mathrm{NH}_{4}{ }^{+}\right.$) 925.4540 , found 925.4536.

\section{Dibenzyl (2,3,5-tri-O-tert-butyldiphenylsilyl-1-13C-B-p-arabinofuranosyl)-1-} phosphate (S4). To a stirring solution of azeotropically dried (toluene, $3 \times 5 \mathrm{~mL}$ ) S3 (0.2822 g, $0.3110 \mathrm{mmol}$ ) in dichloromethane (3.1) was added TMSBr (0.0820 mL, 0.622 $\mathrm{mmol}$ ) dropwise. The reaction was stirred at rt for $6 \mathrm{~h}$. Meanwhile, in a separate flask dibenzyl phosphoric acid ( $0.173 \mathrm{~g}$, $0.622 \mathrm{mmol}$ ) was azeotropically dried with toluene ( $3 \mathrm{x}$ $1 \mathrm{~mL})$. To the dried dibenzyl phosphoric acid were added $4 \AA$ molecular sieves $(0.2311 \mathrm{~g})$, toluene $(1.83 \mathrm{~mL}, 0.17 \mathrm{M})$, and freshly distilled triethylamine (TEA) $(0.11 \mathrm{~mL}, 0.815$ $\mathrm{mmol})$. The crude glycosyl bromide was concentrated under reduced pressure, azeotropically dried with toluene $(3 \times 1 \mathrm{~mL})$, and redissolved in toluene $(0.5 \mathrm{~mL})$. The solution of glycosyl bromide was added via cannula to the solution of dibenzyl phosphoric acid stirring at $\mathrm{O}^{\circ} \mathrm{C}$. The transfer was completed with toluene $(2 \times 0.5 \mathrm{~mL})$. The stirring suspension was slowly brought to rt and stirred overnight. The crude material was filtered through a celite pad and concentrated. The product was obtained by flash column chromatography on silica gel eluting with $15 \%$ EtOAc in hexanes. The product-containing fractions were pooled and evaporated under reduced pressure to provide $\mathbf{S} 4(0.135 \mathrm{~g}, 37$ $\%$ ) as a colorless oil. ${ }^{1} \mathrm{H}$ NMR (500 MHz, Chloroform- $d$ ) $\delta 7.72-7.04(\mathrm{~m}, 4 \mathrm{OH}), 5.76$ (ddd, $J=176.7,4.9,3.1 \mathrm{~Hz}, 1 \mathrm{H}), 4.98(\mathrm{dd}, J=11.9,6.9 \mathrm{~Hz}, 1 \mathrm{H}), 4.87(\mathrm{dd}, J=11.9,7.7 \mathrm{~Hz}, 1 \mathrm{H})$, $4.77(\mathrm{~d}, J=6.6 \mathrm{~Hz}, 2 \mathrm{H}), 4.32(\mathrm{dt}, J=3.5,1.8 \mathrm{~Hz}, 1 \mathrm{H}), 4.27-4.20(\mathrm{~m}, 1 \mathrm{H}), 4.12(\mathrm{q}, J=3.1$ $\mathrm{Hz}, 1 \mathrm{H}), 3.71$ (dd, $J=10.4,7.2 \mathrm{~Hz}, 1 \mathrm{H}), 3.6 \mathrm{o}(\mathrm{dd}, J=10.4,6.9 \mathrm{~Hz}, 1 \mathrm{H}), 0.92(\mathrm{~d}, J=2.9 \mathrm{~Hz}$, $18 \mathrm{H}), 0.86(\mathrm{~s}, 9 \mathrm{H})$. ${ }^{13 \mathrm{C}} \mathrm{NMR}\left(126 \mathrm{MHz}, \mathrm{CDCl}_{3}\right) \delta$ 136.01, 135.99, 135.93, 135.87, 135.80, $135.77,135.66,135.49,133.49,133.26$, 133.0o, 132.62, 132.58, 129.78, 129.73, 129.68, 129.55, 129.51, 128.40, 128.34, 128.32, 128.16, 128.13, 127.78, 127.68, 127.67, 127.65, 127.59, 127.52, 100.85, 100.80, 86.82, 78.19, 78.12, 78.09, 78.06, 77.85, 77.78, 75.41, 68.96, 68.92, 68.80, 68.76, 64.53, 26.84, 26.81, 26.74, 19.26, 19.08. HRMS (ESI-TOF ${ }^{+}$) calc'd for $\mathrm{C}_{66}{ }^{13} \mathrm{CH}_{81} \mathrm{NO}_{8} \mathrm{PSi}_{3}\left(\mathrm{M}+\mathrm{NH}_{4}^{+}\right)$1143.5036, found 1143.5048 .

Bis-triethylammonium (2,3,5-tri-O-tert-butyldiphenylsilyl-1-13C- $B$ - $\mathrm{D}^{-}$ arabinofuran-osyl)-1-phosphate (S5). To a flask containing $\mathbf{S} 4$ (0.1305 g, 0.114 $\mathrm{mmol}), \mathrm{Pd} / \mathrm{C}(8.45 \mathrm{mg}, 0.008 \mathrm{mmol})$, and TEA (0.40 mL, $2.8 \mathrm{mmol})$ in $10 \% \mathrm{EtOH}$ in EtOAc (4.0 mL, $0.03 \mathrm{M}$ ) was added a balloon of hydrogen. The flask was vented with a 
needle to replace the atmosphere and the balloon was refilled with hydrogen. The mixture was stirred for $48 \mathrm{~h}$ at which point the reaction appeared to be complete by TLC. The balloon was removed, the atmosphere exchanged with argon, and the reaction was filtered through a pad of celite and sand. The pad was washed with additional 10\% EtOH in EtOAc. The filtrate was evaporated to yield $\mathbf{S} 5(0.1179 \mathrm{~g}, 90 \%)$ as a white powder that was used in the next reaction without further purification. ${ }^{1} \mathrm{H} \mathrm{NMR}$ (500 $\left.\mathrm{MHz}, \mathrm{CHCl}_{3}-d\right) \delta 7.71(\mathrm{~m}$, $2 \mathrm{H}), 7.61-7.53(\mathrm{~m}, 2 \mathrm{H}), 7.5 \mathrm{O}(\mathrm{d}, J=6.9 \mathrm{~Hz}, 2 \mathrm{H}), 7.44(\mathrm{~d}, J=6.8 \mathrm{~Hz}, 2 \mathrm{H}), 7.4 \mathrm{O}-7.20(\mathrm{~m}$, $14 \mathrm{H}$ ), 7.15 (m, 4H), 7.08 (t, $J=7.6 \mathrm{~Hz}, 2 \mathrm{H}$ ), 5.89 (ddd, $J=170.7,7.4,3.0 \mathrm{~Hz}, 1 \mathrm{H}$ ), 4.23 (d, $J=4.7 \mathrm{~Hz}, 1 \mathrm{H}), 4.10-4.03(\mathrm{~m}, 2 \mathrm{H}), 3.71$ (dd, $J=10.3,7.2 \mathrm{~Hz}, 1 \mathrm{H}), 3.54$ (dd, $J=10.3,7.2$ $\mathrm{Hz}, 1 \mathrm{H}), 2.91$ (q, $J=7.3 \mathrm{~Hz}, 8 \mathrm{H}), 1.17$ (t, $J=7.3 \mathrm{~Hz}, 12 \mathrm{H}), 0.92(\mathrm{~s}, 9 \mathrm{H}), 0.91$ (s, 9H), 0.85 (s, 9H). ${ }^{13 \mathrm{C}} \mathrm{NMR}\left(126 \mathrm{MHz}, \mathrm{CDCl}_{3}\right.$ ) $\delta$ 136.57, 135.84, 135.76, 135.70, 135.67, 135.64, 135.57, 135.53, 133.92, 133.59, 133.57, 133.40, 132.82, 132.44, 129.56, 129.49, 129.45, 129.43, 129.21, 127.64, 127.59, 127.55, 127.53, 127.47, 104.80, 104.76, 99.72 (d), 85.28, 78.70 (d), 78.12 (dd), 71.49, 64.99, 45.30, 27.00, 26.82, 19.39, 19.15, 19.05, 8.50. HRMS (ESI-TOF ${ }^{+}$) calc'd for $\mathrm{C}_{52}{ }^{13} \mathrm{CH}_{64} \mathrm{O}_{8} \mathrm{PSi}_{3}(\mathrm{M}+\mathrm{H})$ 946.3832, found 946.3852 .

(Z,Z)-Farnesylphosphoryl-1-13C-B-p-arabinofuranose (8). (Z,Z)-farnesol (0.0913 g, $0.410 \mathrm{mmol}$ ) and $\mathbf{S} 5$ (0.1179 g, $0.103 \mathrm{mmol})$ were combined in a vial and azeotropically dried with pyridine $(3 \times 0.5 \mathrm{~mL})$. The mixture was taken up in pyridine $(1.4 \mathrm{~mL}, 0.075 \mathrm{M})$ and trichloroacetonitrile $(0.10 \mathrm{~mL}, 1.03 \mathrm{mmol})$ was added dropwise. The resulting solution was stirred at $55^{\circ} \mathrm{C}$ overnight. The reaction was cooled, and the solvent was removed under reduced pressure. The product was carried on to deprotection without further purification.

To the residue was added $15 \%$ concentrated $\mathrm{NH}_{4} \mathrm{OH}$ in methanol $(1 \mathrm{~mL}, 0.5 \mathrm{M})$ and the reaction was stirred until everything was dissolved. To the stirred solution, $\mathrm{NH}_{4} \mathrm{~F}(0.9681$ $\mathrm{g}, 2.61 \mathrm{mmol}$ ) was added under argon. The resulting suspension was stirred at $55{ }^{\circ} \mathrm{C}$ overnight. The mixture was cooled, dichloromethane $(1 \mathrm{~mL})$ was added to precipitate any remaining $\mathrm{NH}_{4} \mathrm{~F}$, and the precipitate was removed by filtration through celite and sand. The solvent was evaporated under reduced pressure. Purification was accomplished by flash silica chromatography eluting with $10 \% \mathrm{MeOH}$ / dichloromethane to $1 \% \mathrm{H}_{2} \mathrm{O} / 20 \% \mathrm{MeOH} /$ dichloromethane. Residual colored impurities were removed by addition of decolorizing carbon to the product in methanol and filtration through a syringe filter. Upon removal of the solvent under reduced pressure 8 was afforded as a colorless oil (0.014 g, 31\%). ${ }^{1} \mathrm{H}$ NMR (500 MHz, Methanol- $\left.d_{4}\right) \delta 5.53(\mathrm{dt}, J=177.4,3.8 \mathrm{~Hz}, 1 \mathrm{H}), 5.45(\mathrm{t}, J=6.5 \mathrm{~Hz}, 1 \mathrm{H}), 5.21-$ $5.08(\mathrm{~m}, 2 \mathrm{H}), 4.48(\mathrm{t}, J=6.7 \mathrm{~Hz}, 2 \mathrm{H}), 4.11(\mathrm{t}, J=7.5 \mathrm{~Hz}, 1 \mathrm{H}), 4.07-4.00(\mathrm{~m}, 1 \mathrm{H}), 3.84(\mathrm{tt}$, $J=6.4,3.1 \mathrm{~Hz}, 1 \mathrm{H}), 3.79$ (dd, $J=12.0,3.2 \mathrm{~Hz}, 1 \mathrm{H}), 3.67$ (dd, $J=12.1,6.0 \mathrm{~Hz}, 1 \mathrm{H}), 3.18$ (q, $J$ $=7.3 \mathrm{~Hz}, 2 \mathrm{H}), 2.18-2.02(\mathrm{~m}, 9 \mathrm{H}), 1.75(\mathrm{~d}, J=1.4 \mathrm{~Hz}, 3 \mathrm{H}), 1.7 \mathrm{O}(\mathrm{dd}, J=2.9,1.4 \mathrm{~Hz}, 7 \mathrm{H})$, $1.63(\mathrm{~d}, J=1.3 \mathrm{~Hz}, 4 \mathrm{H}), 1.31(\mathrm{t}, J=7.3 \mathrm{~Hz}, 3 \mathrm{H}) .{ }^{13 \mathrm{C}} \mathrm{NMR}(126 \mathrm{MHz}, \mathrm{MeOD}) \delta$ 141.08, 136.71 , 132.48, 125.88, 125.51, 123.39, 123.33, 99.22 (d), 85.08, 79.31 (dd), 75.37, 64.23, 63.58, 63.54, 47.84, 33.42, 33.04, 27.79, 27.71, 26.10, 23.87, 23.82, 17.91, 9.32. HRMS (ESI-TOF ${ }^{+}$) calc'd for $\mathrm{C}_{19}{ }^{13} \mathrm{CH}_{34} \mathrm{O}_{8} \mathrm{P}\left(\mathrm{M}^{-}\right)$434.2030, found 434.2032. 

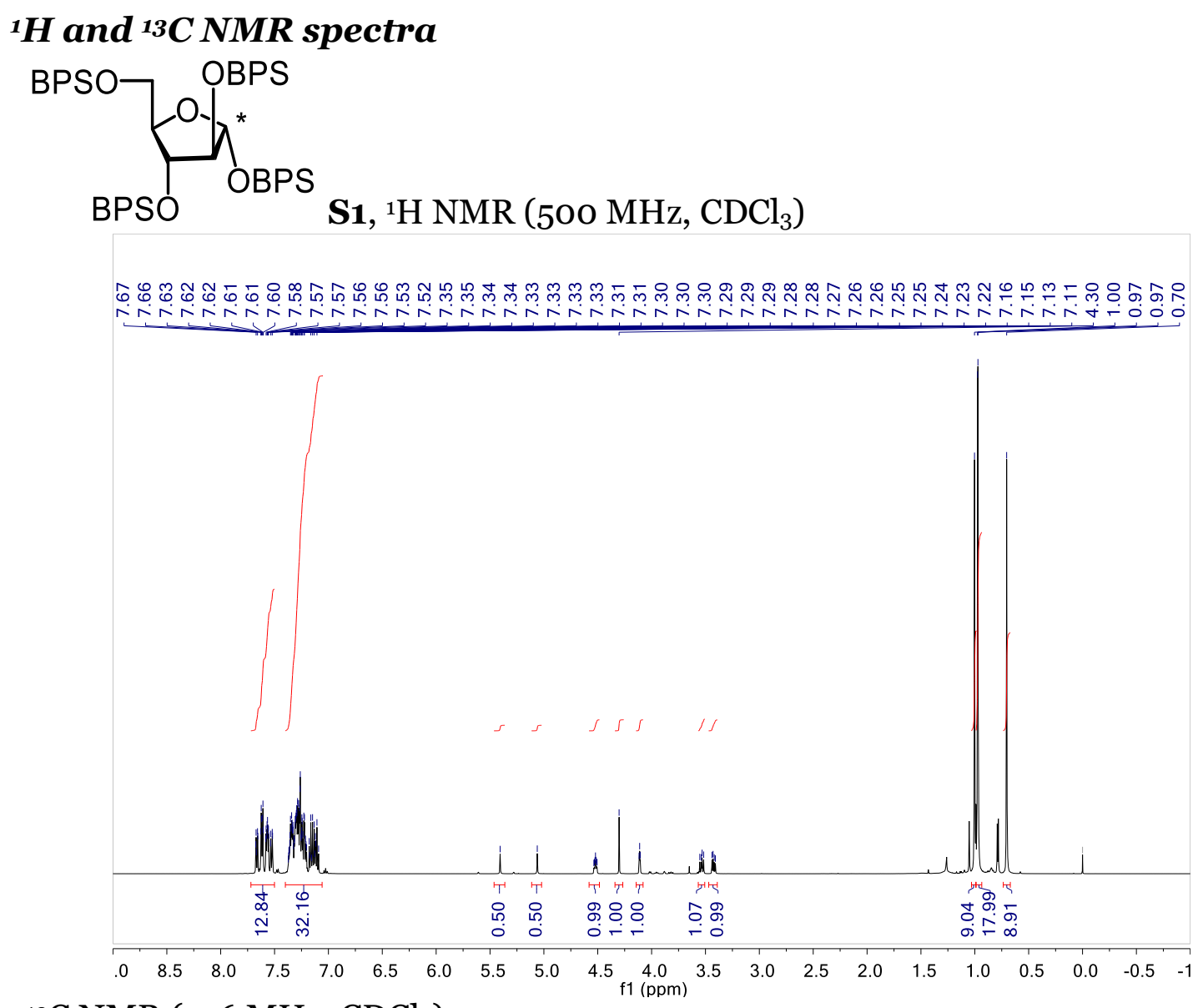

13C NMR (126 MHz, $\mathrm{CDCl}_{3}$ )

\%

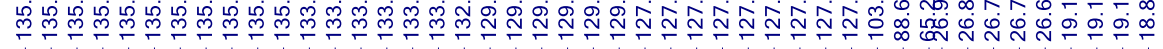

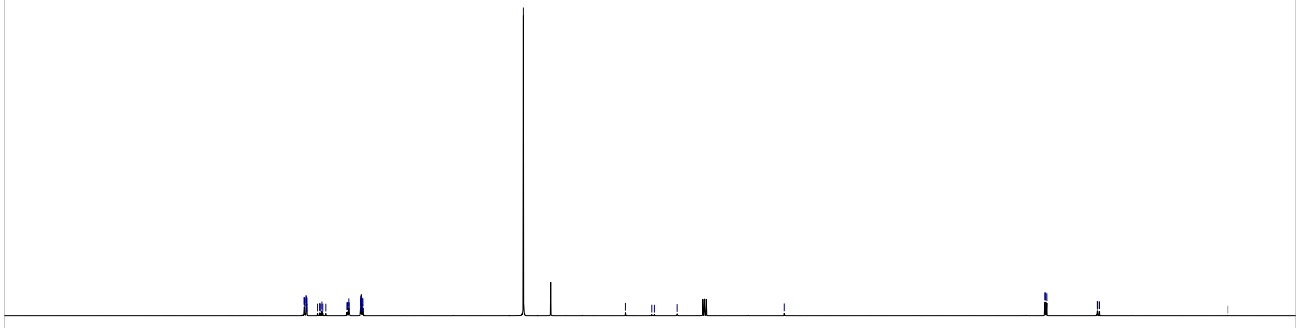

80

$\begin{array}{llllllllll}170 & 160 & 150 & 140 & 130 & 120 & 110 & 100 & 90 & 80 \\ \mathrm{f} 1(\mathrm{ppm})\end{array}$ 


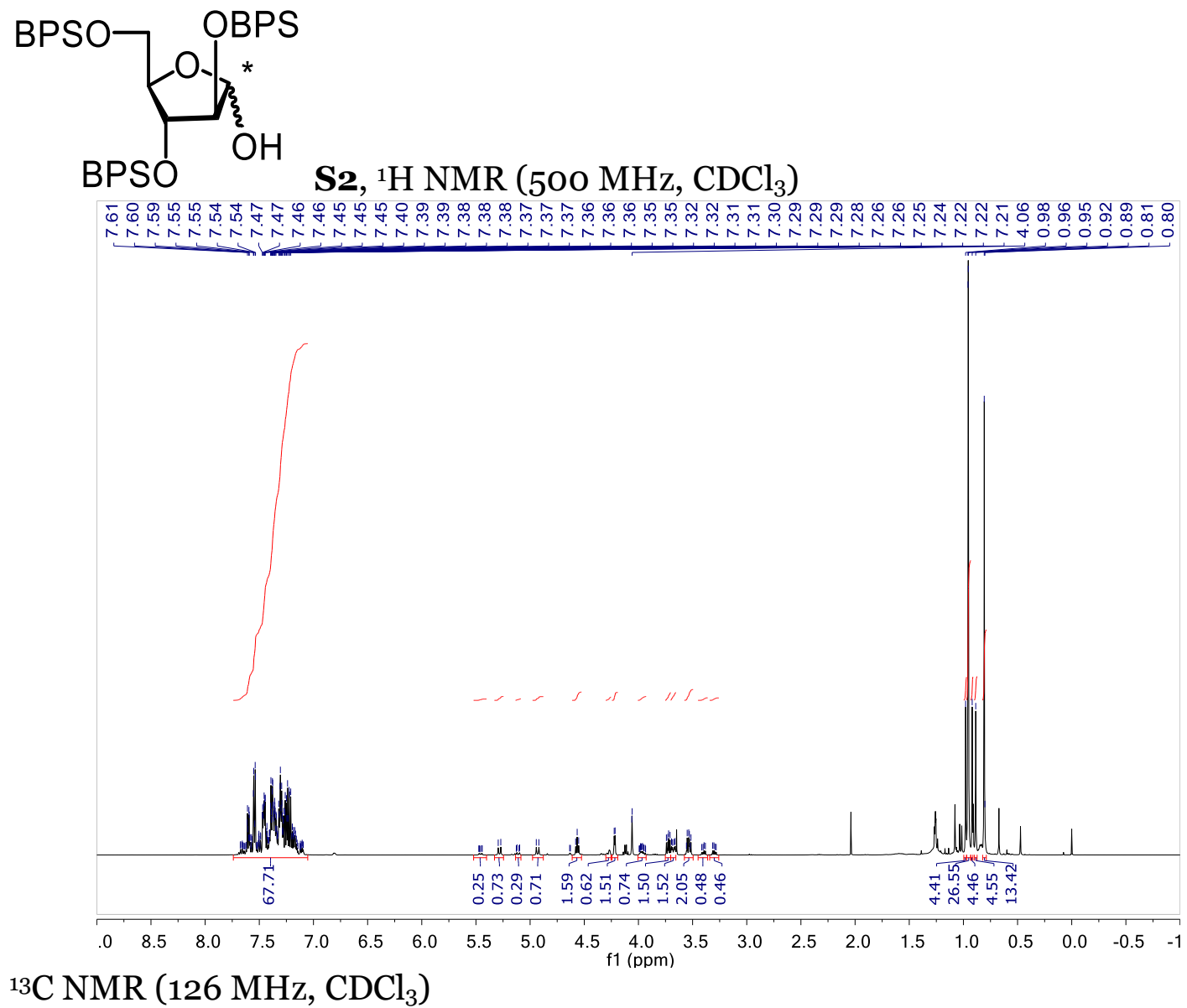

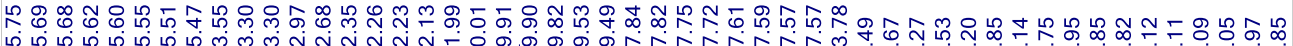

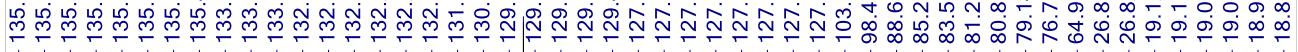

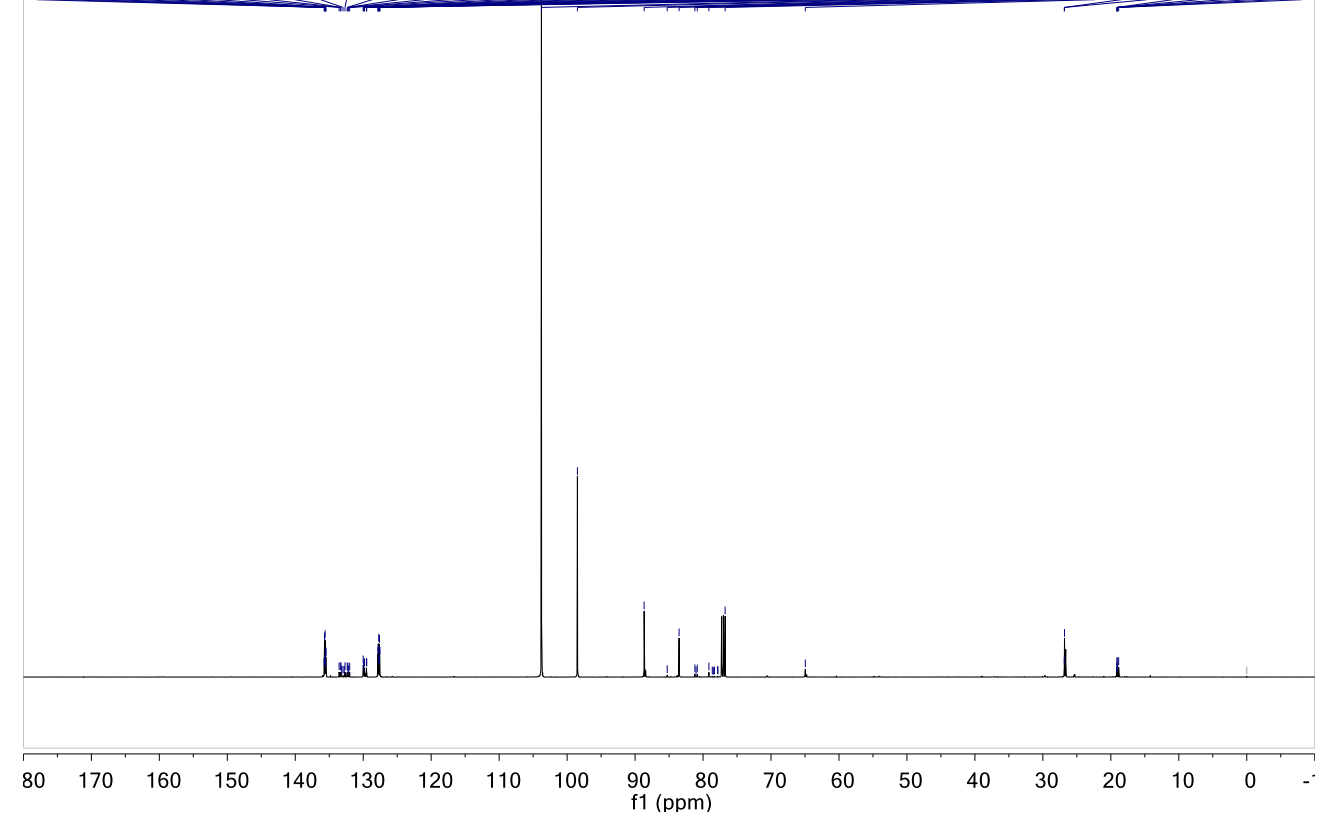




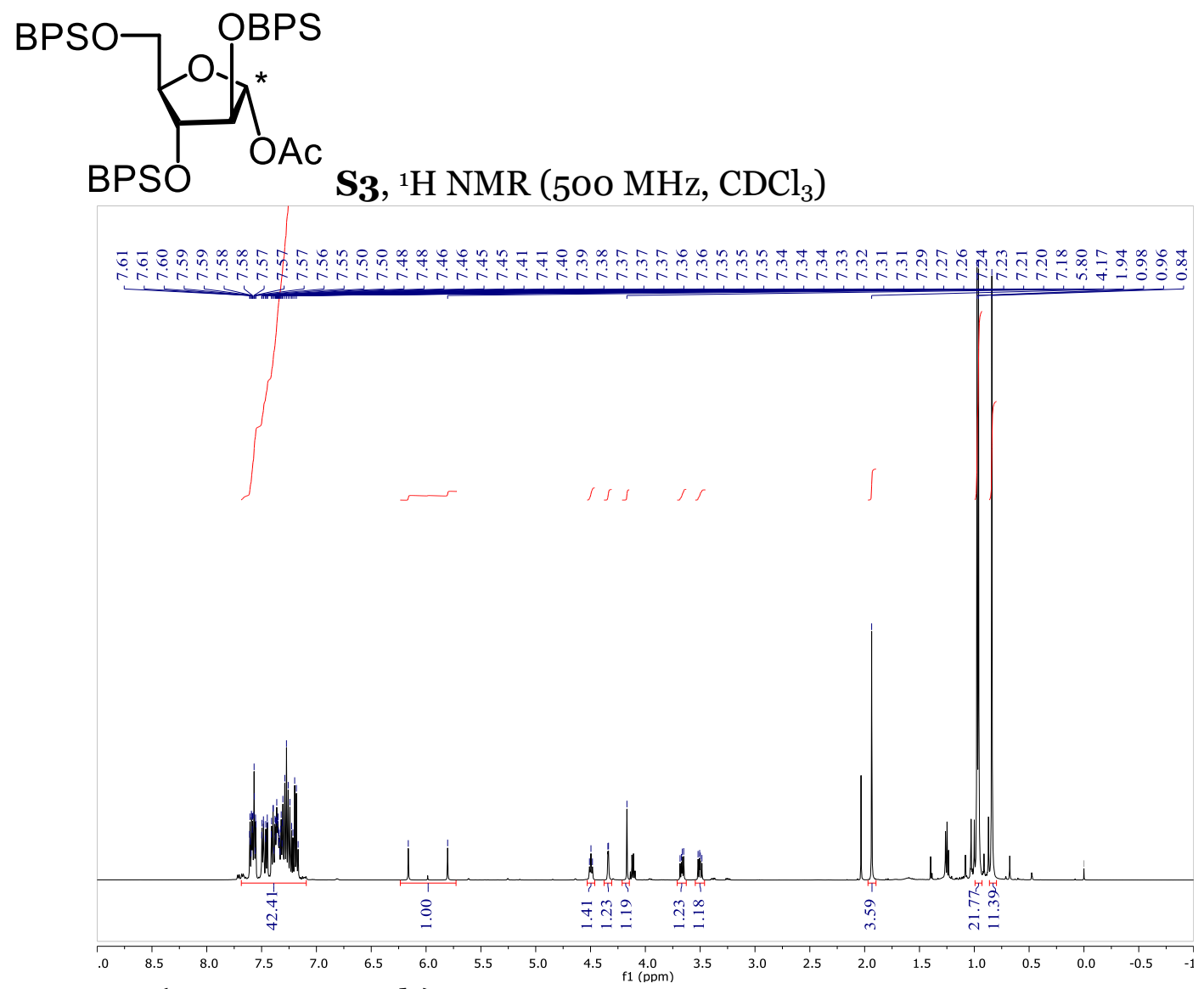

13C NMR (126 MHz, $\mathrm{CDCl}_{3}$ )
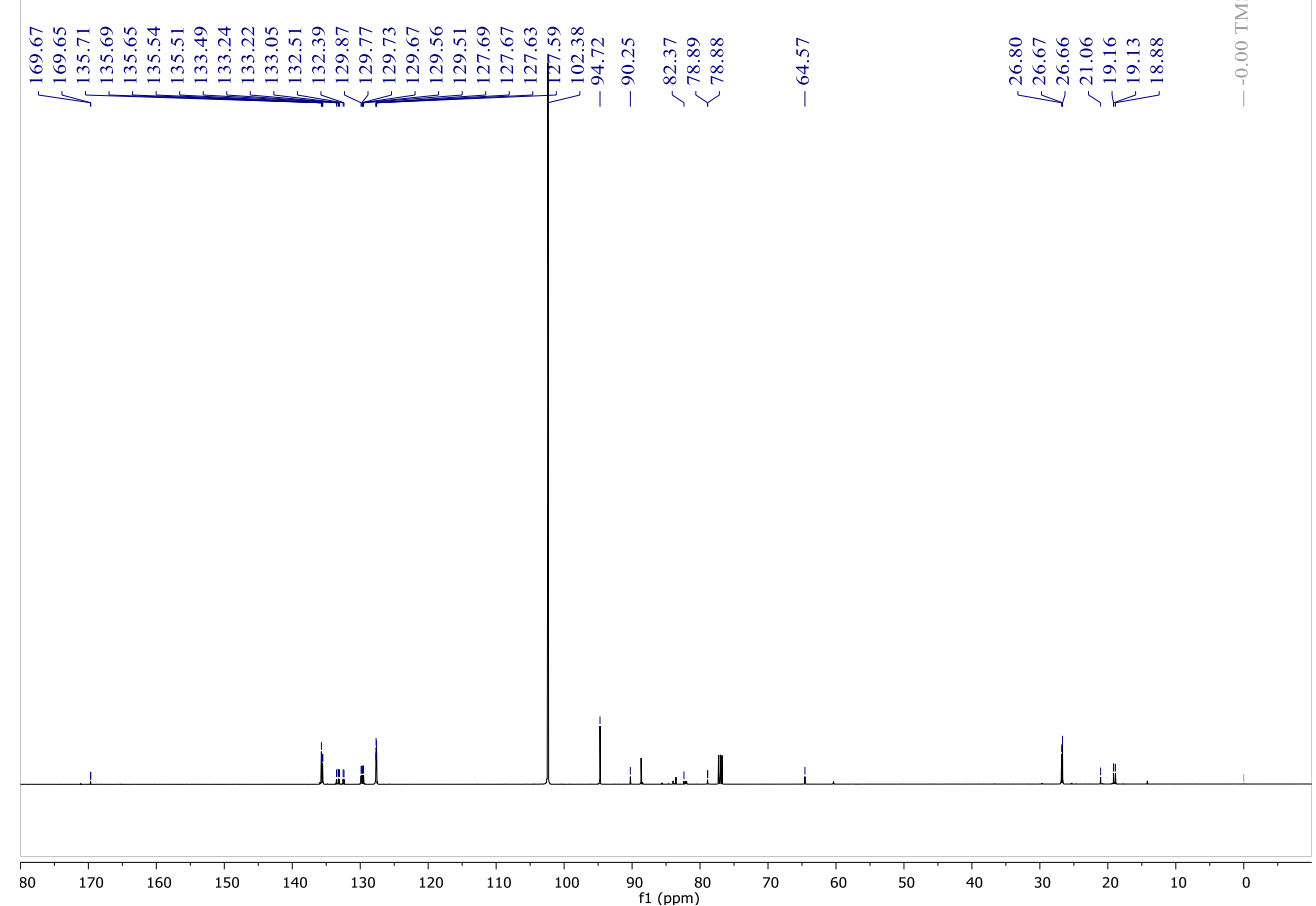


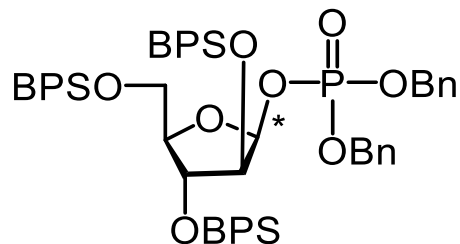

S4, ${ }^{1} \mathrm{H}$ NMR $\left(500 \mathrm{MHz}, \mathrm{CDCl}_{3}\right)$

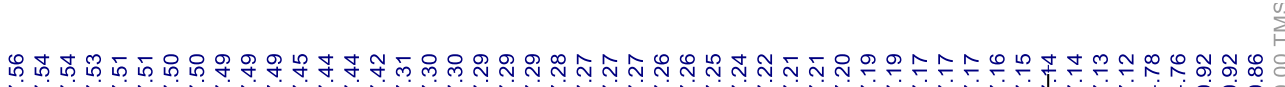

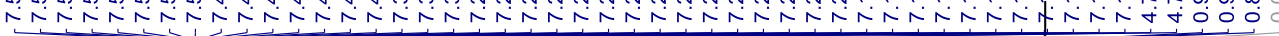
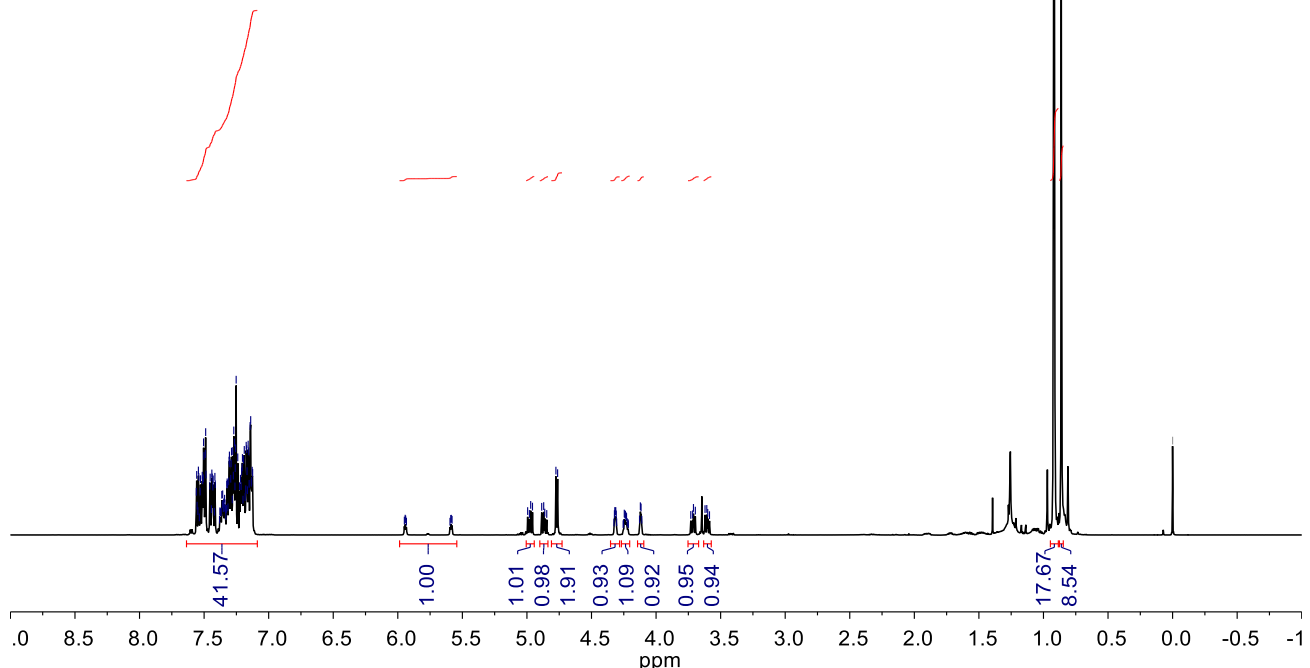
13C NMR (126 MHz, $\mathrm{CDCl}_{3}$ )

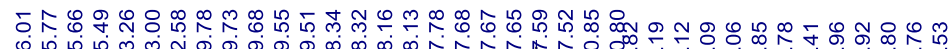

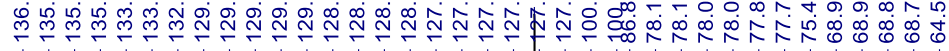

苾市

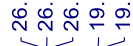

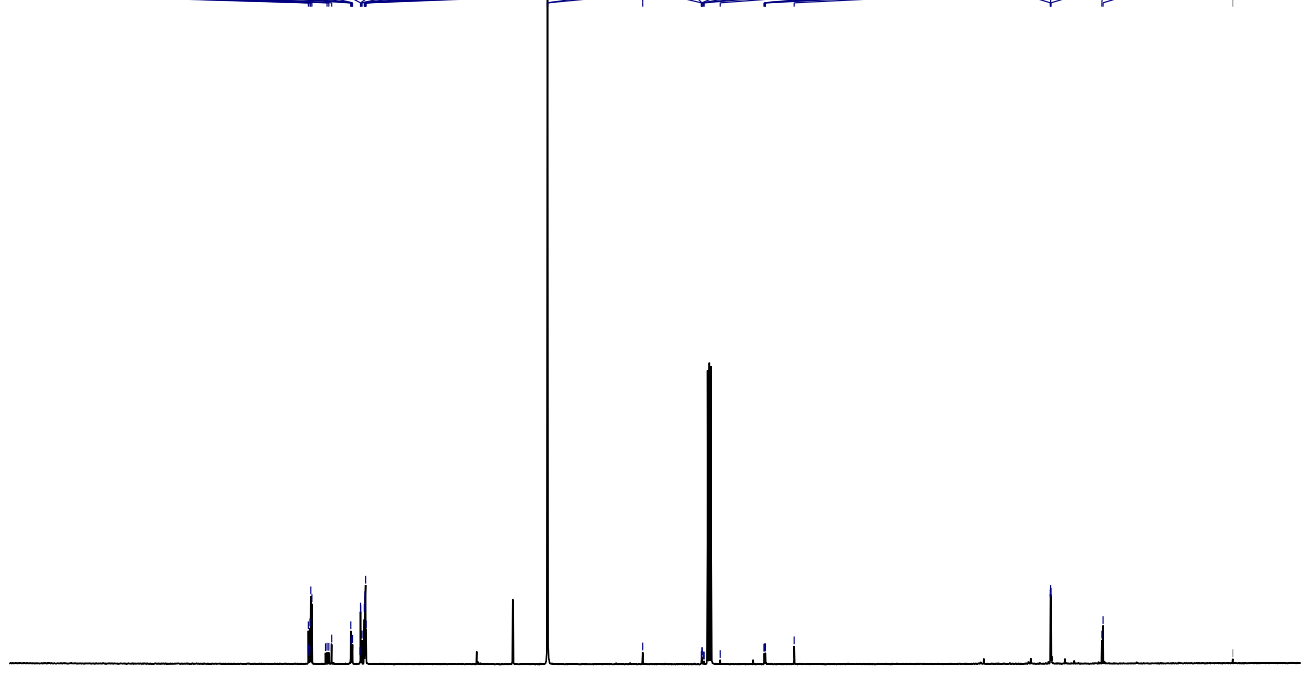

80

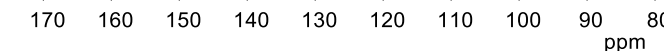




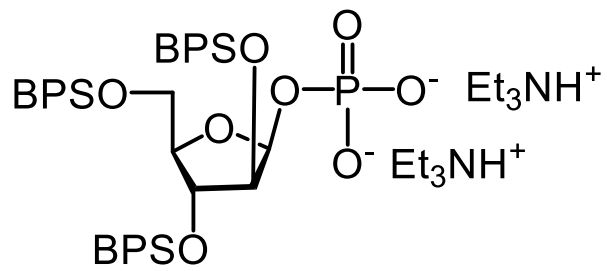

S5, ${ }^{1} \mathrm{H}$ NMR (5OO MHz, $\left.\mathrm{CDCl}_{3}\right)$

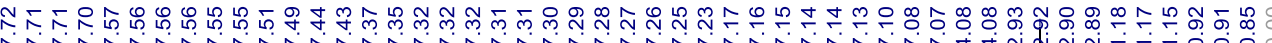

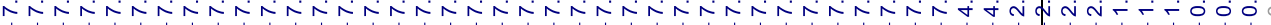

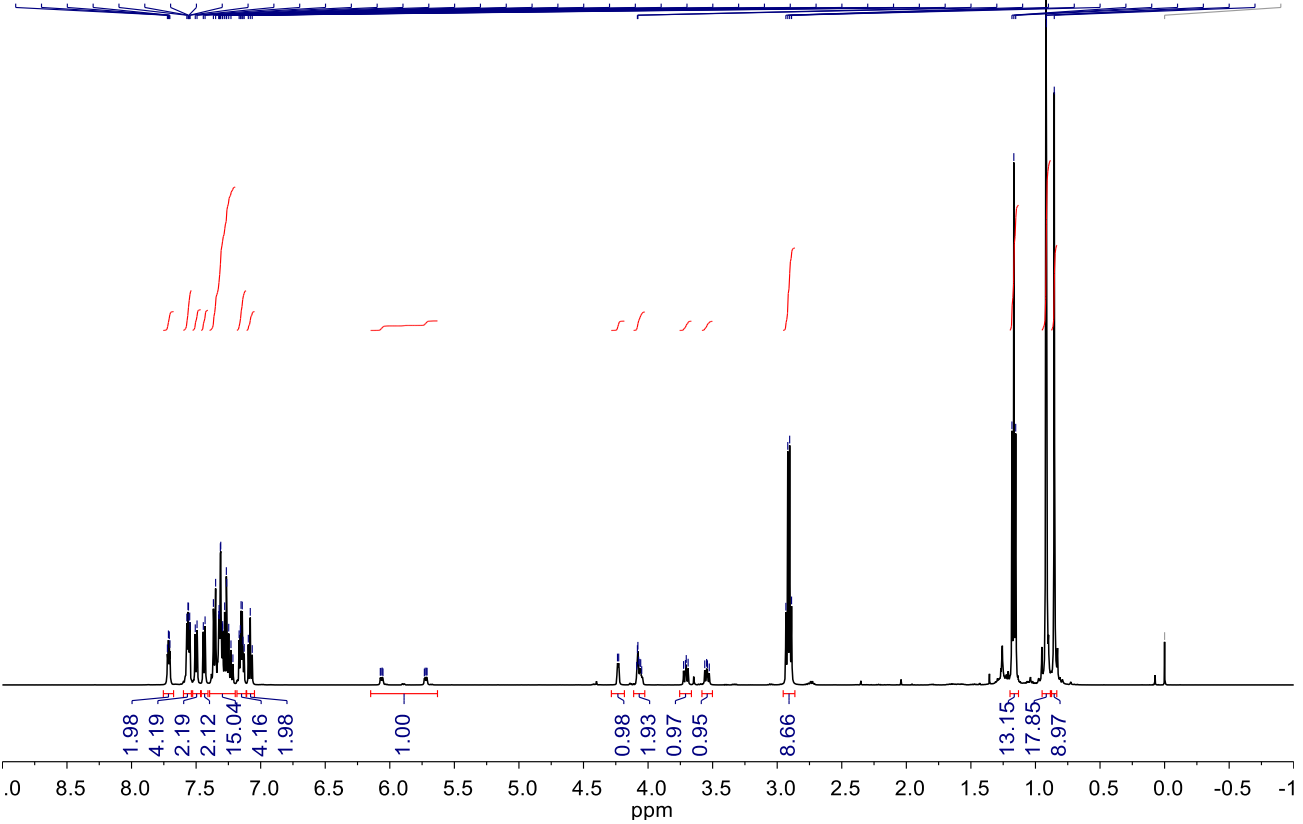

13C NMR (126 MHz, $\mathrm{CDCl}_{3}$ )

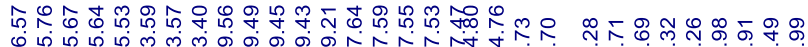

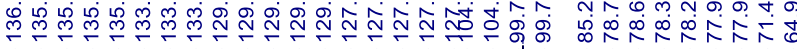

年

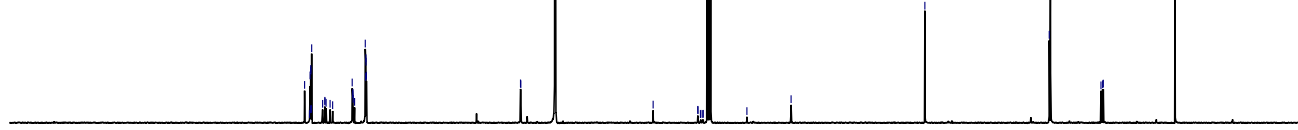

80

$\begin{array}{lllllllll}170 & 160 & 150 & 140 & 130 & 120 & 110 & 100 & 90 \quad 0_{\text {ppm }}^{80}\end{array}$ 


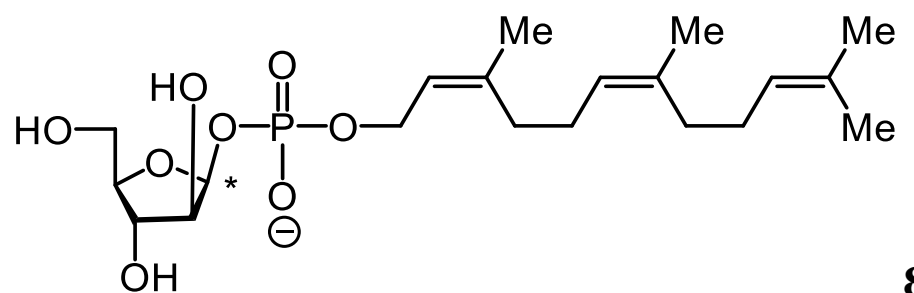

8, ${ }^{1} \mathrm{H}$ NMR $\left(500 \mathrm{MHz}, \mathrm{CDCl}_{3}\right)$

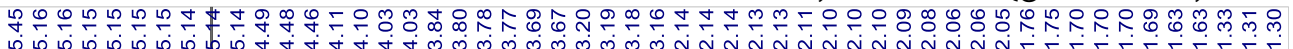

ถڤถ

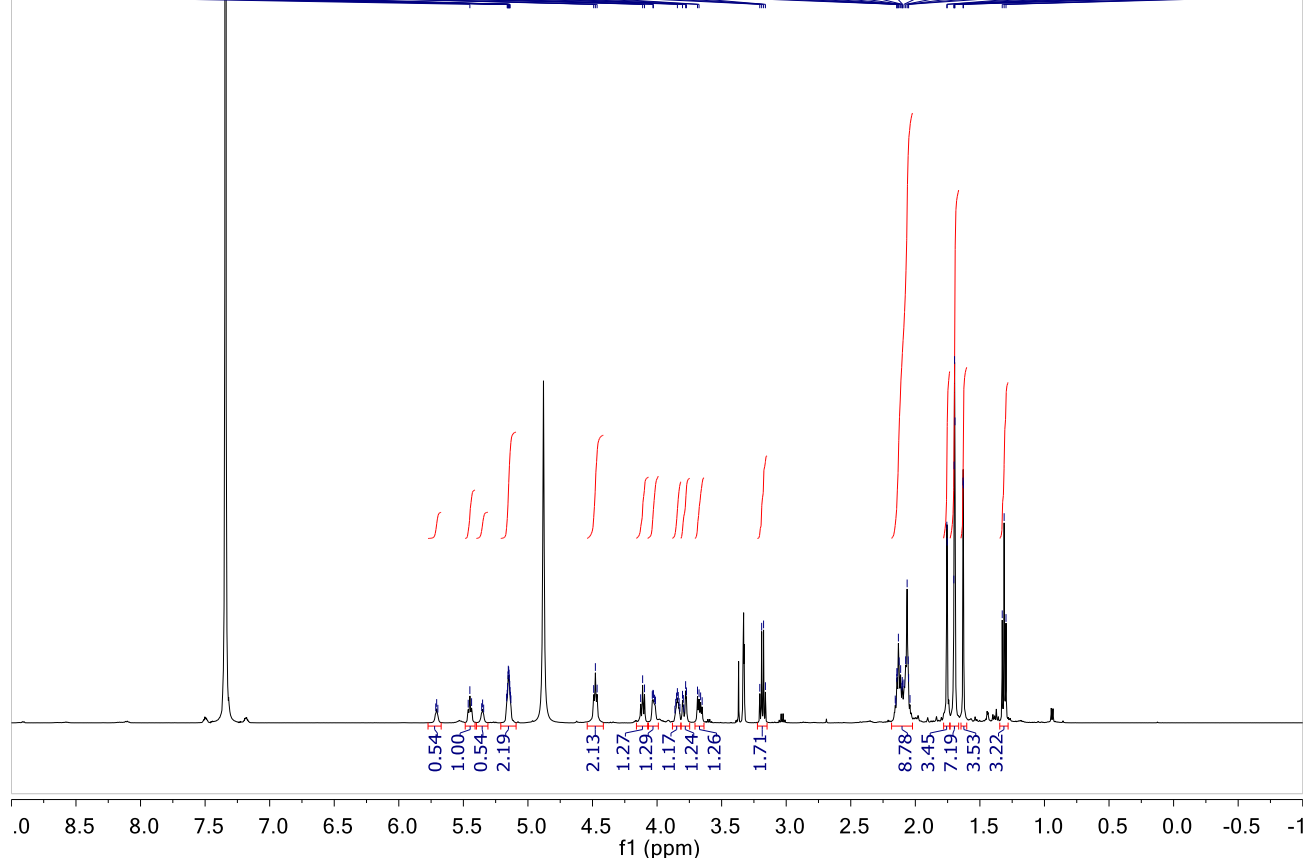

13C NMR (126 MHz, $\left.\mathrm{CDCl}_{3}\right)$

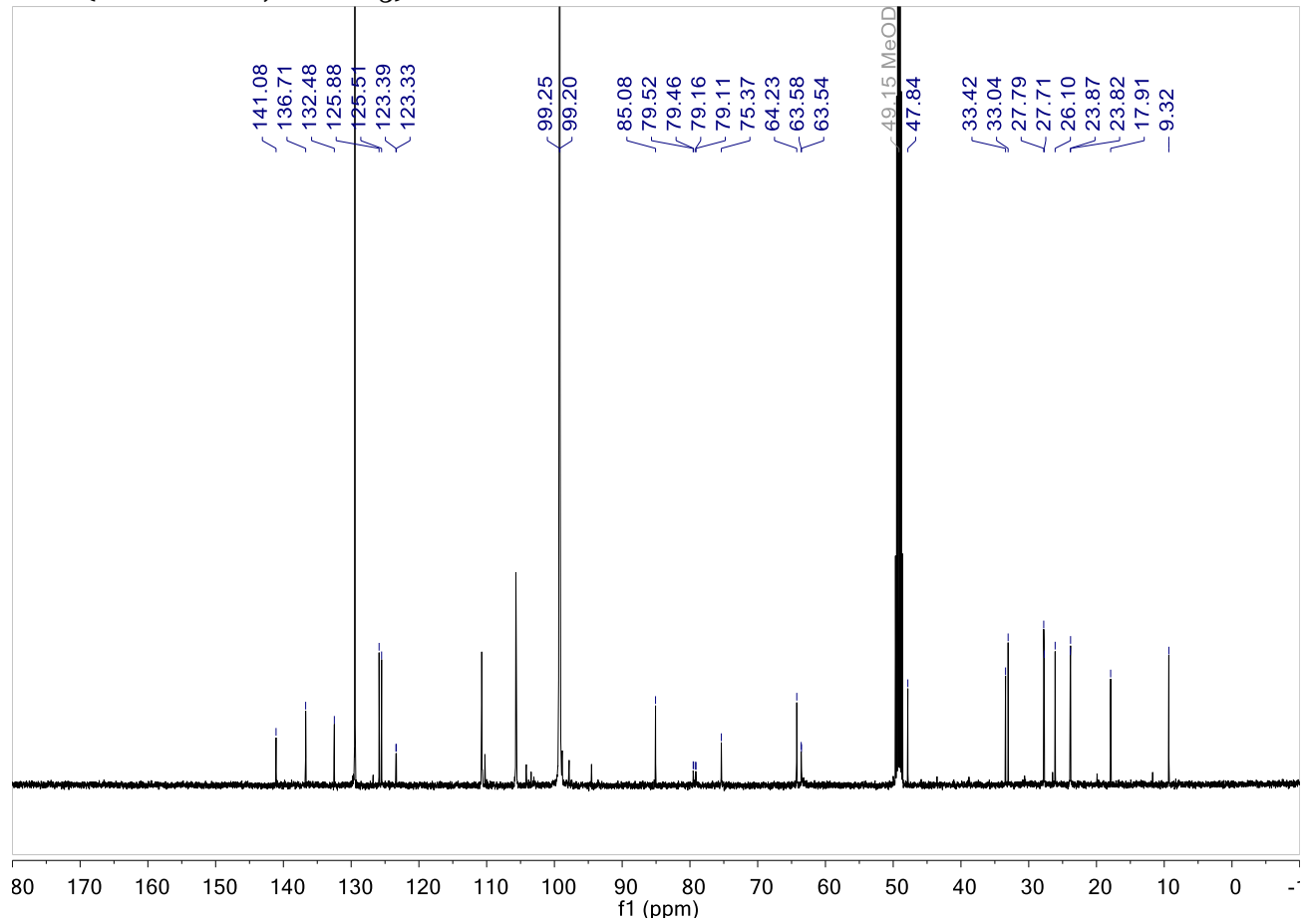




\section{Supplemental References}

1. Lee, R. E.; Li, W.; Chatterjee, D.; Lee, R. E., Rapid structural characterization of the arabinogalactan and lipoarabinomannan in live mycobacterial cells using $2 \mathrm{D}$ and $3 \mathrm{D}$ HRMAS NMR: structural changes in the arabinan due to ethambutol treatment and gene mutation are observed. Glycobiology 2005, 15 (2), 139-51.

2. Shiloh, M. U.; Ruan, J.; Nathan, C., Evaluation of bacterial survival and phagocyte function with a fluorescence-based microplate assay. Infect. Immun. 1997, 65 (8), 3193.

3. Kraft, M. B.; Martinez Farias, M. A.; Kiessling, L. L., Synthesis of lipid-linked arabinofuranose donors for glycosyltransferases. J. Org. Chem. 2013, 78 (5), 2128-33. 